NBER WORKING PAPER SERIES

LEGALITY AND REALITY:

SOME EVIDENCE ON CRIMINAL PROCEDURE

William M. Landes

Work1ng Paper No. 40

CENTER POR ECONOMIC ANALYSIS OF HUMAN BEHAVIOR AND SOCIAL INSTITUTIONS National Bureau of Economic Research. Inc.

$261 \mathrm{Mad}$ ison Avenue, New York, N.Y. 10016

May 1974

Preliminary; Not for Quotation

NBER working papers are distributed informally and in limited number for comments only. They should not be quoted without written permission.

Th1s report has not undergone the revlew accorded officlal NBER nublications; in particular, it has not yet been submitted for approval by the Board of Directors.

The research reported herein was performed pursuant to a grant from the National Science Foundation to the NBER for research in the area of law and economics. The opinions expressed herein are those of the author and do not necessarily reflect the views of the National Sclence Foundation. 


\section{Legality and Reality: Some Evidence on Criminal Procedure*}

\section{William M. Landes}

University of Chicago and National Bureau of Economic Research

There is widespread concern that the criminal justice system, particularly in large urban areas, is breaking down under the strain of an increasing demand for $i$ ts services and inadequate resources. At the center of the system, located between the police and the prisons, are the criminal courts. Allegedly, the courts no longer serve the interest of law-abiding citizens or the constitutional rights of persons accused of crimes. Defendants are treated capriciously with the guilty and dangerous recycled through the courts and set free within hours of their arrest, while the innocent languish in jail for lack of bail funds. Statistics on rising crime rates, recidivism, arbitrary sentencing practices, court delay, and prison riots are taken as further evidence that the courts are failing. What has been notably scarcer is systematic empirical 
research on the criminal court system--research that can contribute to our understanding of the actual workings of the system and enable us to develop policies for improvement. The purpose of this study is to begin to remedy this deficiency by applying the quantitative techniques of economics to an analysis of some important issues in criminal court procedure.

The theoretical framework for the study is based on my two recent papers on the courts and on the bail system. 1/ In these papers, I advanced hypotheses on the determination of bail, and the effects of pretrial status and other variables on plea bargaining, sentencing and other methods of disposition. In this study, I attempt to test these hypotheses using a rich source of data: a random sample of 858 defendants in criminal court in New York City in 1971 containing detailed information on the defendant's prior criminal record and socio-economic characteristics, the criminal charges against the defendant, the various court proceedings involving the defendant, and the outcome of the case.

The paper is organized as follows. Section I describes the sample and defines the variables used in the study. Section II contains an empirical analysis of the determinants of pretrial status where we analyze the factors determining the terms on which a defendant may obtain his pretrial liberty. Section III, the main section of the paper, tests whether the factors determining pretrial liberty are also significant predictors of the amount of harm a defendant will do if released on bail. This enables us to distinguish between the two dominant hypotheses on the social function of bail. The first asserts that the primary function of a bail system is to ensure the defendant's appearance at trial; the second emphasizes the desirability of using the bail process as a means of preventing future 
crimes by defendants. 2/ Our empirical analysis reveals that the second hypothesis is more consistent with actual behavior: the factors that lead to the setting of higher bail bonds (which, in turn, are shown to reduce the likelihood of pretrial liberty) are significant predictors of the likelihood of committing crimes during the period of pretrial liberty but have little predictive power in explaining the high disappearance rate (around 30 per cent) of persons released on bail. This finding, which is the main contribution of the study, provides a powerful rationale (that is, the prevention of future crimes during the period of pretrial liberty) for the operation of the current bail system-though a rationale that some would argue is inadequate when weighed against the restrictions imposed on the rights of the accused. Section IV focuses on the disposition of cases where we examine the role of pretrial detention, delay and other variables on the outcome of cases. Section $V$ summarizes our findings and présents concluding remarks.

I. The Data

The data for our study is a random sample of 858 defendants in New York County who were represented by the Legal Aid Society during the year 1971. 3/ The sample was limited to defendants whose arraignment took place in the first half of 1971, and whose cases were in the Society's closed files as of December 15, 1971. Cases were placed in the closed files if there were no further proceedings involving the defendant. Thus, our sample consists of completed cases which allows us to trace each defendant through the courts from his arraignment to the final disposition of his case. 4/ The sample excludes females, juveniles, and youthful offenders. (roughly, males under 21 years of age), defendants who replaced 
Legal Aid counsel with private counsel, and defendants whose cases were disposed of at the time of their arraignment. A defendant's arraignment takes place within 24 hours of his arrest, and a substantial proportion (roughly 37 per cent of cases in the Society's closed files) are completed at this time. Frequently, the charges against the defendant are dismissed at the arraignment because the complaining witness does not appear. Since the procedural questions we seek to investigate do not come into play until after the arraignment, the exclusion of these cases is consistent with our overal1 interest.

There are other limitations to the data that should be noted. Legal Aid is restricted to low income defendants. However, the majority of criminal defendants in New York City have low incomes as evidenced by the fact that the Legal Aid Society serves as counsel to about 70 per cent of all defendants in New York. $5 /$ The similarity between our sample of Legal Aid defendants and all criminal defendants in New York City is apparent from the data presented in Table 1 on the method of disposition of cases, the proportion of defendants not appearing, and the proportion of Supreme Court cases. $6 /$ One must also be cautious about deriving inferences on the operation of the criminal justice system in the U.S. from data

limited to low income defendants in New York, particularly in view of the belief that New York's judicial system is more overburdened and closer to collapse than that of other large cities. Finally, it would be incorrect to treat the sample as representative of the population of criminal offenders in New York or elsewhere. Defendants are persons arrested and charged with a crime and their characteristics may be very different than a sample that also included offenders who were not apprehended. 
Table 1

Criminal Defendants in N.Y. County Logal Aid Sample, New York County and New York City in 1971

\begin{tabular}{llll}
\hline \hline & Sample & $\begin{array}{c}\text { N.Y. County } \\
\text { (Manhattan) }\end{array}$ & N.Y.C. \\
\hline $\begin{array}{l}\text { Total Cases Disposed } \\
\text { Percent Trials }\end{array}$ & 667 & 83,254 & 220,590 \\
Percent Dismissed & 1 & 2 & 3 \\
Percent Guilty Pleas & 33 & 47 & 52 \\
Disappeared as Percent of Disposed & $19^{\mathrm{b}}$ & 51 & 45 \\
Supreme Court as Percent of Disposed & 10 & $23^{\mathrm{c}}$ & $31^{c}$ \\
\end{tabular}

axcludes defendants whose cases went to the Supreme Court of N.Y. State (67 defendants in our sample) and cases where the defendant disappeared (124 defendants in our sample). Note that disappearances took place in 9 supreme court cases giving a total of 133 disappearances in our sample.

befendants who failed to appear and were placed in the Legal Aid society's closed files.

CDisappeared are estimated by warrants iseued after defendant failed to appear. After the warrant is issued, the defendant may appear and have his case disposed.

donly includes supreme court cases that initially arose in Criminal court.

Source: N.Y. County and N.Y.C. data from Annual Report of the Criminal Court of the City of New York, 1971, pp. 4, 39, and 40. 
Table 2 presents a portrait of defendants in the sample classified by the type of offense and the severity of the charge. The sample is widely distributed among offense types with the largest proportion of defendants (29 per cent) accused of drug offenses (including both possession and sale with the former being the less severe offense). I/ With respect

to the severity of the charge, the majority of defendants in the sample are accused of felonies (61 per cent). Since defendants are typically charged with multiple offenses, the severity and offense class are determined by the most severe charge against the defendant. The second part of Table 2 indicates the New York Penal Code penalties (in years) for the various felony and misdemeanor charges. These penalties in turn are the basis for a rough index of the severity of the charge against the defendants (see Table 3).

For convenience we present in Table 3 a list of the variables used in the empirical analysis. The definitions of the variables given in the table are brief and where necessary they are supplemented in the text. For further reference we also include in Table 3 the means and standard deviations of the variables.

\section{Pretrial Status}

The pretrial status of a person arrested and charged with a crime is affected by the court's decision regarding the terms on which the defendant may obtain his pretrial release, and the defendant's demand for release or his ability and willingness to meet the terms set by the court. The first part of this section investigates the former question. We analyze 
Table 2

Type and Severity of Offense

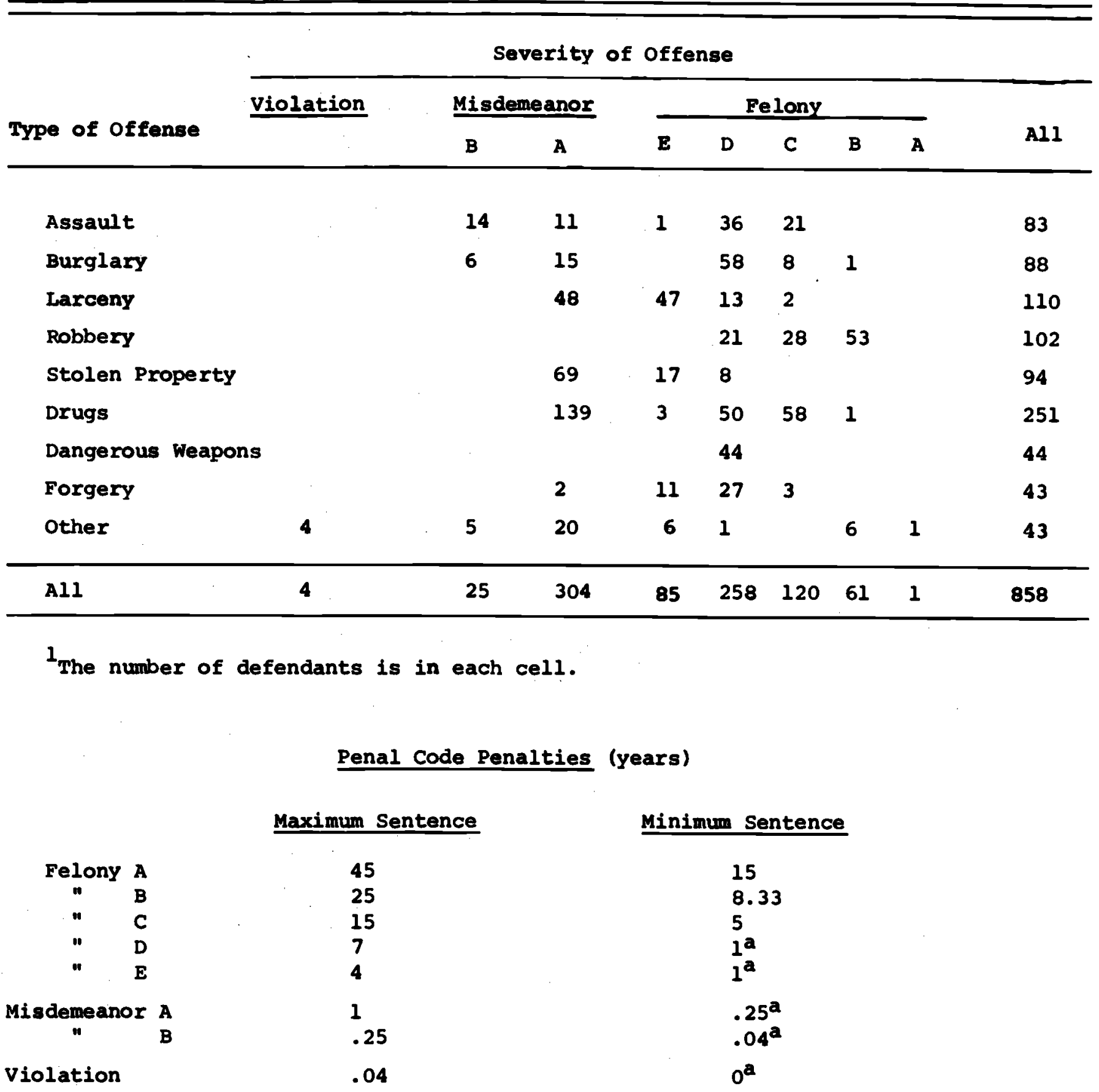

No minimum sentences given. Maximum of next lesser charge was used except Misdemeanor $A$ used as minimum for felony $D$. 


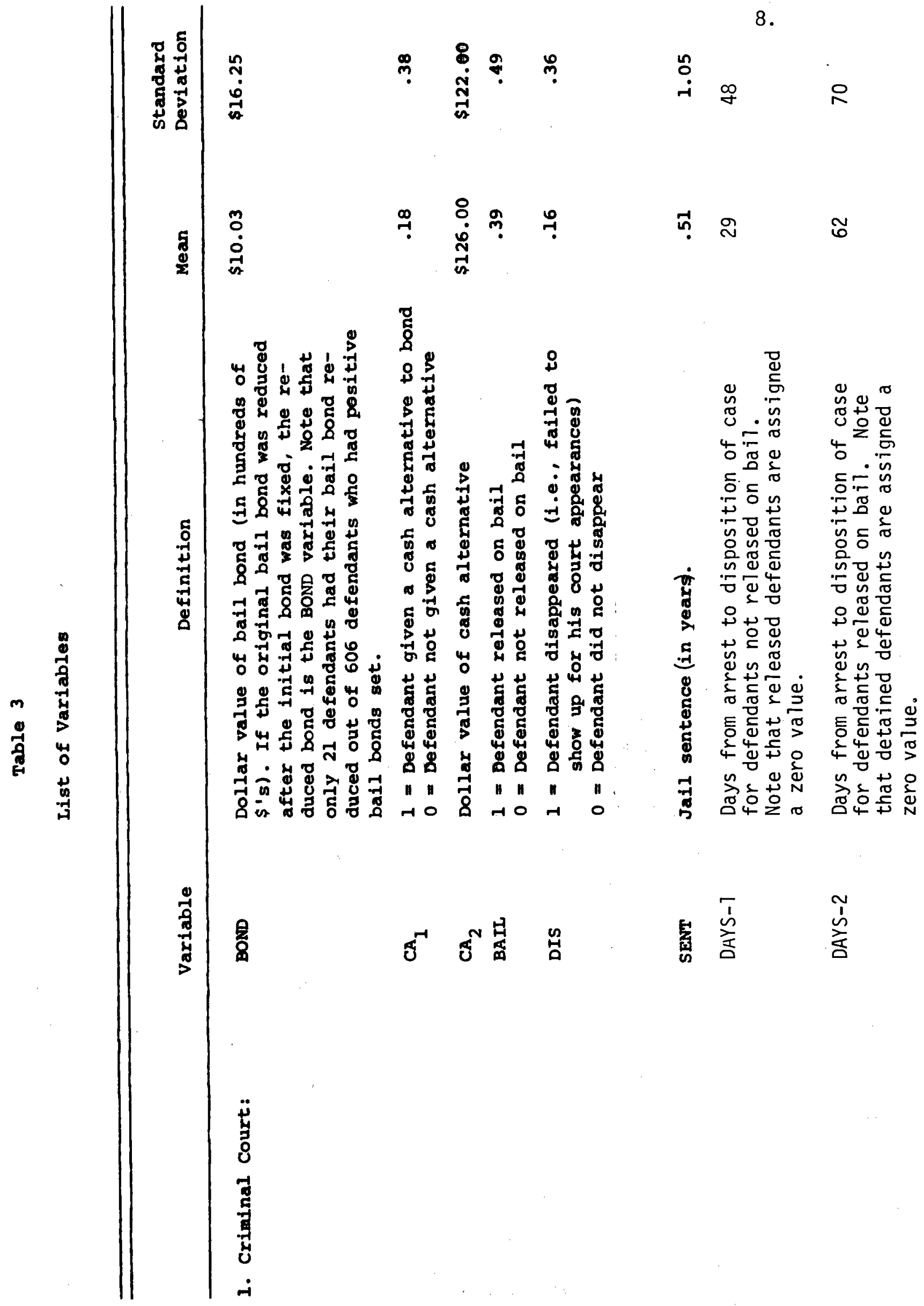




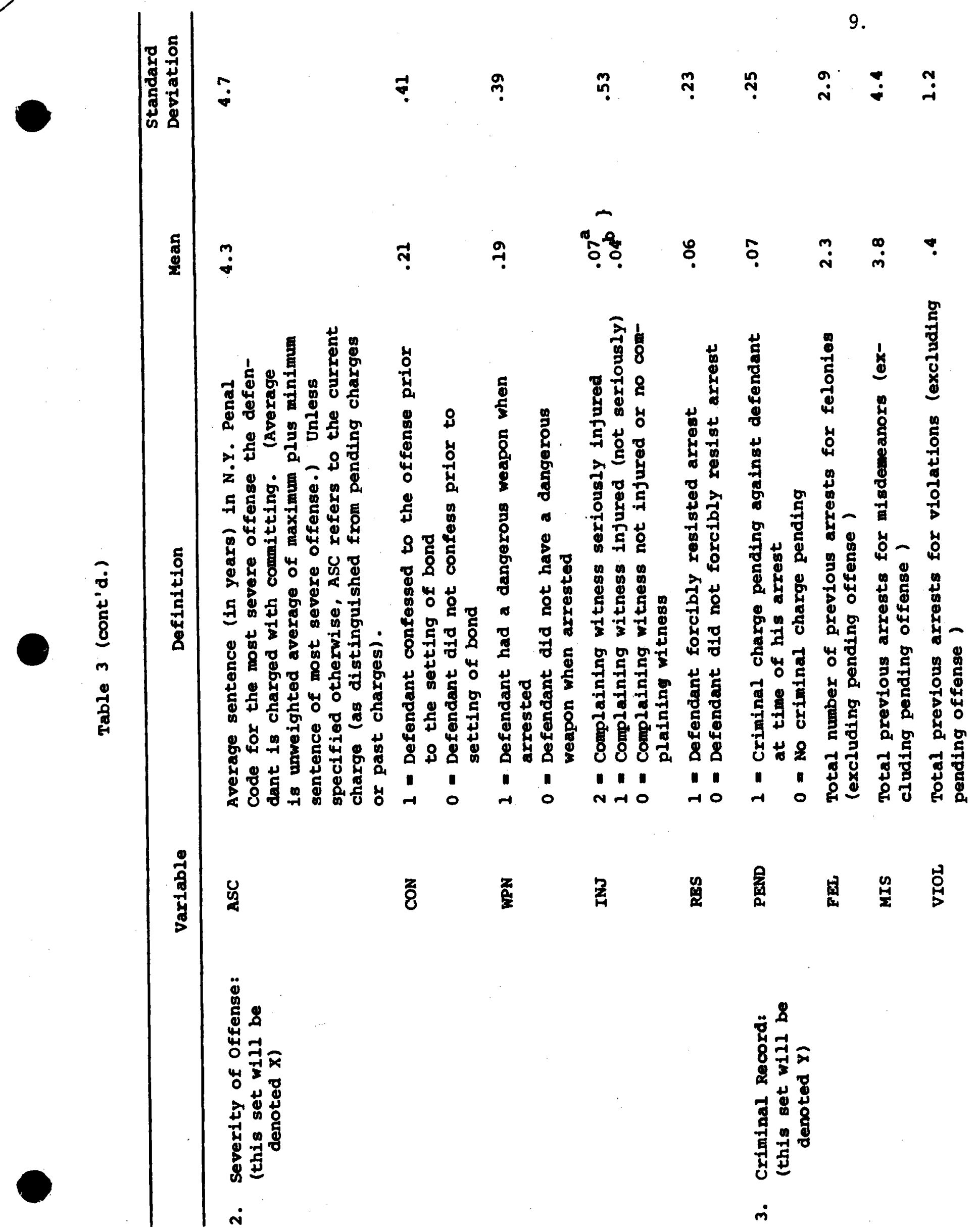




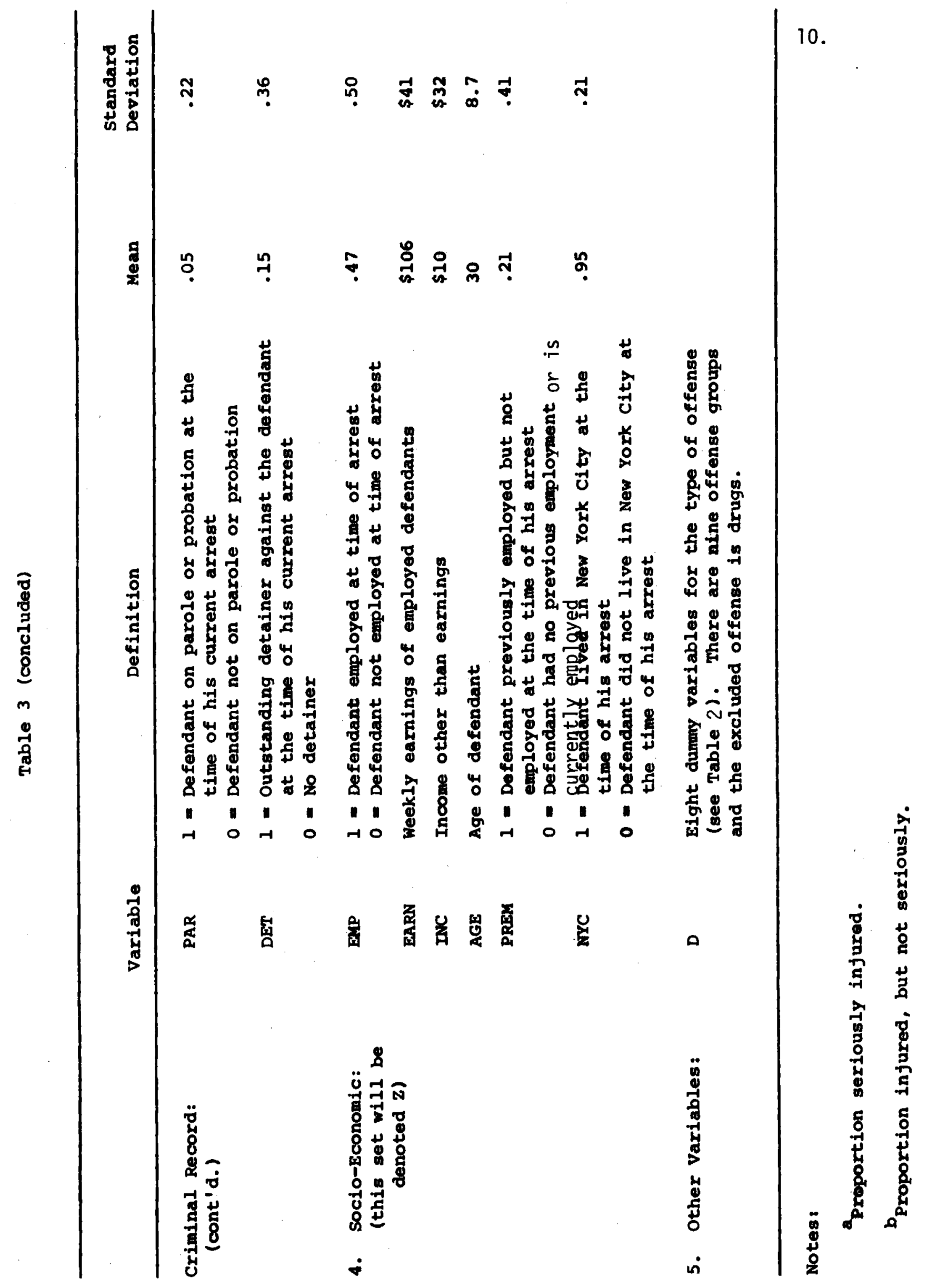


the factors determining the size of the bail bond, and the related question of whether the defendant is offered the option of a cash alternative (that is, depositing a relatively small amount of cash as an alternative to posting a bail bond). The second part of this section analyses the empirical determinants of the defendant's demand for pretrial release with particular reference to the effects of the "price" charged for release and the defendant's socio-economic characteristics. The Determination of Bond

Multiple regression equations were estimated on the dependent variable, the dollar value of the bond set by the court. The specification of the regression equation is as follows:

$$
\text { BOND }_{i}=\beta_{0}+\beta_{1} X_{i}+\beta_{2} Y_{i}+\beta_{3} Z_{i}+\beta_{4} D_{i}+u_{i}
$$

where $X, Y, Z$ and $D$ are vectors of severity of offense variables, criminal record variables, socio-economic variables and dummy offense variables respectively, $u$ is the residual, and the subscript $i$ denotes the particular defendant. (See Table 3 for the definition of variables included in these classes.)

The purpose of including in equation (1) variables measuring the severity of the offense (the $X$ vector) and the defendant's prior record (the $Y$ vector) is based on two hypotheses:

Hypothesis I. The size of the bond is a position function of the harm the defendant is expected to do if released where harm includes either or both (a) the likelihood the defendant will interfere with the proceedings against him (primarily by fleeing or not appearing), and (b) the potential dangerousness of the defendant in terms of crimes committed during the period of pretrial 1iberty. 8 / 
Hypothesis II. The severity of offense variables (except for possibly the confession variable) and the prior record variables are positively related to the amount of harm a defendant will do if released on bail. In other words, these variables provide information on harm (Hypothesis II), and this information is then utilized by judges (Hypothesis I) in setting bond. We will assume provisionally that the second hypothesis is in fact true, and test the first hypothesis by examining whether the severity of the offense and prior record variables are positively related to the size of bond in equation ( 1 ).

The variables included in the severity of offense category require further explanation. The severity of the formal charge (the ASC variable) is a direct estimate of the severity of the offense that allegedly took place. 9/ According to Hypotheses I and II this variable should have a positive and significant effect on the size of the bail bond. The inclusion of other variables in the severity of offense category is based on the possible inaccuracy of the ASC variable alone. For example, the more serious the injury to a complaining witness (i.e., the victim), holding the formal charge constant, the greater the actual severity of the crime and hence (according to hypotheses I and II) the greater the size of bond. 10/ Or defendants resisting arrest or having weapons in their possession at the time of their arrest, holding the formal charge constant, may be considered to have committed a more dangerous offense and hence will have higher bail bonds. 11/ The final variable included (somewhat arbitrarily) in the severity of offense category is whether the defendant confessed prior to setting the bond (the CON variable). We are uncertain about the expected effect of this variable on bond. $\underline{12}$ / 
24. F.

55 continued

rate of disappearance by setting more difficult terms for pretrial release may still be a goal of the bail system but according to our empirical results this goal would be equally/served by setting bond randomly among defendants. One rationale of setting bond on the basis of the severity and extent of one's prior record is to prevent defendants with greater probabilities of committing crimes from obtaining pretrial liberty. Note that one can never totally reject the hypothesis that judges are attempting to forecast the probability of disappearance in setting bond since it is conceivable that they are attempting to do so but are unsuccessfur in their efforts.

56. It must be noted that our empirical findings are not intended as either an indictment or defense of the existing bail system. We have quantified certain statistical relationships between bail setting and pretrial harm, but have not attempted to measure the social costs of operating the bail system in comparison to the gains from preventing pretrial crimes. For example, although the factors used in setting bond also predict pretrial crime, they may be subject to considerable error. Thus, detained defendants may have higher probabilities of committing crimes during pretrial liberty than those not released, and yet a majority of those detained may not commit any crime had they been released. Moreover, if the aim of public policy were exclusively the prevention of pretrial crime, the ideal solution would be to jail every defendant. 
Table 4

Regression Coefficients and T-Values on the Size of Bond

Equation No.

4.1

4.2

4.3

\begin{tabular}{|c|c|c|c|c|c|c|}
\hline & \multicolumn{2}{|c|}{ BOND } & \multicolumn{2}{|c|}{ BOND } & \multicolumn{2}{|c|}{ BOND } \\
\hline & $\begin{array}{l}\text { Regression } \\
\text { Coefficient }\end{array}$ & (T-value) & $\begin{array}{l}\text { Regression } \\
\text { Coefficient }\end{array}$ & (T-value) & $\begin{array}{l}\text { Regression } \\
\text { Coefficient }\end{array}$ & (T-value) \\
\hline ASC & 1.391 & $(13.332)$ & 1.448 & $(13.116)$ & 1.357 & $(11.526)$ \\
\hline FEL & 1.151 & $(5.607)$ & 1.070 & $(4.895)$ & .966 & $(4.408)$ \\
\hline MIS & .260 & $(1.969)$ & .260 & $(1.848)$ & .267 & $(1.862)$ \\
\hline VIOL & .114 & $(.281)$ & .301 & $(.669)$ & .323 & $(.718)$ \\
\hline PEND & 4.670 & $(2.415)$ & 5.735 & $(2.670)$ & 5.466 & $(2.477)$ \\
\hline AGE & -.021 & $(.365)$ & -.014 & $(.229)$ & -.024 & $(.379)$ \\
\hline PAR & & & & & 5.660 & $(2.293)$ \\
\hline DET & & & & & 1.737 & $(1.055)$ \\
\hline CON & & & & & -.864 & $(.690)$ \\
\hline WPN & & & & & .041 & $(.028)$ \\
\hline INJ & & & & & 2.145 & $(2.026)$ \\
\hline RES & & & & & 3.410 & $(1.383)$ \\
\hline NYC & & & & & 2.834 & $(1.129)$ \\
\hline EMP & & & & & - & - \\
\hline PREM & & & & & .160 & $(.114)$ \\
\hline EARN & & & & & -.022 & $(2.224)$ \\
\hline INC & & & & & -.014 & $(.852)$ \\
\hline DUM & & & & & 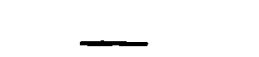 & $\longrightarrow$ \\
\hline CONST & .742 & & .100 & & -1.340 & \\
\hline $\mathbf{R}^{2}$ & .234 & & .243 & & .264 & \\
\hline $\mathbf{N}$ & 858 & & 764 & & 764 & \\
\hline
\end{tabular}


Table 4 (cont'd.)

Regression Coefficients and T-Values on the Size of Bond

Equation No.

4.4

4.5

\begin{tabular}{|c|c|c|c|c|}
\hline & \multicolumn{2}{|l|}{ BOND } & \multicolumn{2}{|c|}{ BOND } \\
\hline & $\begin{array}{l}\text { Regression } \\
\text { Coefficient } \\
\end{array}$ & (T-value) & $\begin{array}{l}\text { Regression } \\
\text { Coefficient } \\
\end{array}$ & (T-Value \\
\hline ASC & 1.367 & $(11.627)$ & 1.213 & $(8.134)$ \\
\hline FEL & .970 & $(4.420)$ & .947 & $(4.311)$ \\
\hline MIS & .281 & $(1.964)$ & .257 & $(1.787)$ \\
\hline VIOL & .305 & $(.678)$ & .234 & $(.518)$ \\
\hline PEND & 5.476 & $(2.479)$ & 5.687 & $(2.558)$ \\
\hline AGE & -.024 & $(.384)$ & .013 & $(.195)$ \\
\hline PAR & 5.639 & $(2.282)$ & 6.182 & $(2.477)$ \\
\hline DET & 1.790 & $(1.085)$ & 1.975 & $(1.193)$ \\
\hline $\mathrm{CON}$ & -.855 & $(.682)$ & -.722 & $(.573)$ \\
\hline WPN & -.023 & $(.016)$ & .649 & $(.354)$ \\
\hline INJ & 2.087 & $(1.971)$ & 3.749 & $(3.012)$ \\
\hline RES & 3.403 & $(1.380)$ & 5.180 & $(2.003)$ \\
\hline NYC & 2.775 & $(1.103)$ & 3.424 & $(1.356)$ \\
\hline EMP & -2.332 & $(1.882)$ & -2.145 & $(1.728)$ \\
\hline PREM & .161 & $(.110)$ & .051 & $(.035)$ \\
\hline EARN & $-\cdots$ & ---- & ...- & -.--- \\
\hline INC & -.013 & $(.811)$ & -.014 & $(.848)$ \\
\hline DUM & $-\cdots$ & --- & $x$ & $(1.33)^{\mathrm{a}}$ \\
\hline CONST & -1.376 & & -2.052 & \\
\hline $\mathrm{R}^{2}$ & .262 & & .273 & \\
\hline$N$ & 764 & & 764 & \\
\hline
\end{tabular}

a F-ratio for 8 dummy offense variables. 
1. The Severity of Offense Variables. Overall, our findings strongly support our predictions. The major indicator of severity, the ASC variable, is positive and the most significant variable in all equations in Table 4. Each additional unit (year) of severity adds on average about $\$ 135$ to the defendant's bond ; for example, a Class $B$ felony compared to a Class E felony is an increase in severity from $21 / 2$ to $162 / 3$ years, which in turn adds about $\$ 1900$ to the size of bond. The most significant of the other severity variables is an injury to the complaining witness (INJ) where a severe injury adds between $\$ 400$ and $\$ 775$ to the defendant's bond, other things constant. The resist arrest variable (RES) has the predicted positive sign in all regressions but is only marginally significant. The remaining severity of offense variables (WPN and CON) have no significant effects on the size of bond.

2. Criminal Record Variables. The criminal record variables behave in a manner that is highly consistent with Hypotheses I and II. Both past felonies (FEL) and past misdemeanors (MIS) have positive and significant effects in all regression equations in Table 4, while past violations (VIOL) have positive but insignificant effects. Of equal importance is the relative rankings of these variables in the estimated regression equations. In particular, a past felony arrest is statistically more significant and has nearly four times the impact on the defendant's bond than a past misdemeanor (for example, a past felony adds about $\$ 100$ to the bond while a past misdemeanor adds about $\$ 25$, other things constant). $15 /$ Since Hypothes is II combines both the severity of the offense and the defendant's criminal record in forecasting the amount of harm from pretrial release, the empirical finding that past felonies have larger 
quantitative effects and are substantially more significant than past misdemeanors and violations is understandable. Felonies are more severe offenses, and hence a record or past felony arrests would indicate that the defendant is expected to do greater harm if released that a defendant with a past record of misdemeanors and violations. 16/ We emphasize some caution in interpreting the FEL, MIS and VIOL variables because they indicate arrests not convictions (though based on the high rate of convictions in the current sample, arrests are probably highly correlated with convictions). The parole or probation variables (PAR) is, however, a measure of a prior conviction and one that may have resulted in a jail sentence. This variable is highly significant and has a strong positive impact on the size of bond in all regressions. A defendant on parole or probation (holding constant prior arrests, the severity of the current charge and other variables) has, on average, to post approximately a $\$ 600$ higher bond to obtain pretrial liberty than a defendant not on parole or probation.

The outstanding detainer variable (DET) has a positive but non-significant effect on the defendant's bond in all regressions in Table 4 . An outstanding detainer is a request to hold the defendant for a variety of reasons such as a parole violation, a bail violation on a pending charge, or a warrant for his arrest in another jurisdiction. 17/ since increasing the size of bond is the principle means of detaining a person, one would expect a positive relationship between bond and the presence of a detainer. Part of the effect on bond of a detainer is picked up by the parole and pending variables, but some additional effect remains though it is not significant.

The final indicator of a defendant's criminal record is the pending 
variable (PEND). A defendant who has a pending charge has in the past been arrested and charged with a crime, released on bail, and then rearrested and charged with committing a new offense (that is, the current charge) during the period of pretrial liberty. $18 /$ One would expect the pending variable to be an important determinant of the bond. Since we are arguing that prior information is a useful predictor of future behavior (Hypothesis II) one predictor of this harm is the fact that the defendant has recently committed a crime during the period of pretrial release. $19 /$ The results contained in Table 4 are consistent with this hypothesis. The regression coefficients on the pending variable are positive and significant in all regressions, and indicate that a pending charge is associated with about a $\$ 500$ increase in the size of the bond holding constant the other variables. $20 /$

3. Socio-Economic Variables. Employment in legal activities (the EMP variable) and the amount of earnings from legal employment (the EARN variable) have significant negative effects on the size of the defendant's bond in equations 4.3-4.5. Forty-seven per cent of the sample are currently employed at the time of their arrest, and their average earnings is $\$ 106$ per week. As weekly earnings rise due to both greater labor force participation and higher hourly wages, the results in Table 4 indicate that the size of bond falls. $21 /$ This is consistent with the view that legal earnings or employment are taken as crude measures of the defendant's "ties" to the community and as indicators of the likelihood that he will appear for subsequent court appearances if released on bail. Whether this variable in fact has any predictive power in forecasting nonappearances by defendants will be tested later. The other socio-economic variables (AGE, NYC, PREM and INC) have no significant effects on the size of bond. Except 
for NYC, the standard errors of these variables are all larger than their respective regression coefficients.

4. The Dummy Offense Variables. Equation 4.5 differs from 4.4 in that eight dummy variables indicating the specific crime category of the defendant's offense have been added to 4.5. The dummy variables are robbery (e.g., $\quad 1$ if the defendant is accused of robbery and 0 if he is not), assault, burglary, stolen property, larceny, forgery, possession of a dangerous weapon and "other" offenses--with the excluded category being drug offenses. We include the dummy variables to answer the following question: Is there anything significant about the particular offense that results in the setting of a lower or higher bail bond once we hold constant the severity of the offense, the defendant's criminal record and his socioeconomic characteristics? The answer for the group of offenses taken together is "no". An F-test performed on the eight dummy variables leads us to accept the null hypothesis that the eight make no significant contribution to the reduction in the residual variance of the equation. 22/ Cash Alternatives to Bond

Up to this point, the empirical analys is has focused on the determinants of the size of the bail bond. However, posting a bond to obtain pretrial release may not be the only option available to the defendant. Some defendants are given the choice between posting a bond or depositing with the court an amount of cash that is typically a small fraction of the bond. The option of a cash alternative will generally reduce the difficulty of making bail since it eliminates the necessity of having access to large sums of cash (for example, cash equal to the amount of the bond) or assets that can be used as collateral for one's bond. Therefore, the 
possibility of cash alternatives means that an analysis of differences in bond amounts alone may not accurately reflect differences in the terms on which defendants may obtain their pretrial release. For example, if one observed that a large proportion of defendants were given the option of a cash alternative and that the proportion increased as the amount of the bond increased, then this would seriously undermine the conclusion that factors such as the severity of the offense, criminal record, etc. are significant determinants of the terms of pretrial release. We can investigate this and related questions using the data presented in Table 5 on the frequency of cash alternatives and their dollar amounts cross-classified by the size of bond.

The results of Table 5 indicate that: (1) the number of defendants with cash alternatives are concentrated in the $\$ 500$ bond category (i.e., 82 per cent of defendants given cash alternatives were in this group); (2) the proportion of defendants given the cash option rapidly declines with the size of bond (except between the $\$ 2000-\$ 3000$ and $\$ 3500-\$ 5000$ classes though the difference between 3.6 and 4.4 per cent is not statistically significant); and (3) the amount of cash alternative tends to rise with the size of bond (except for the sharp decline for the two defendants with cash alternatives in the $\$ 3500-\$ 5000$ bond class). Overall, increases in the size of bond generally understate the difficulty of being released on bail. Hence, our finding based on the bond regressions that the severity of the offense, criminal record, etc., are important determinants of the terms on which the defendant may obtain pretrial liberty is strengthened by the greater likelihood of a cash alternative for a defendant with relatively low bond. 
Table 5

Cash Alternative by the Size of Bond

\begin{tabular}{|c|c|c|c|c|c|c|c|}
\hline \multirow[b]{3}{*}{ endants } & \multicolumn{7}{|c|}{ Size of Bond } \\
\hline & $\$ 500$ & $\$ 1000$ & $\$ 1500$ & $\begin{array}{c}\$ 2000- \\
3000\end{array}$ & $\begin{array}{c}\$ 3500- \\
5000\end{array}$ & $\begin{array}{l}\$ 7500- \\
20,000\end{array}$ & Total \\
\hline & 257 & 131 & 56 & 85 & 45 & 10 & $584^{\mathrm{a}}$ \\
\hline 年 & 120 & 18 & 4 & 3 & 2 & 0 & 147 \\
\hline 1 ALCE & 46.7 & 13.7 & 7.1 & 3.6 & 4.4 & 0 & 25.2 \\
\hline Alternative & $\$ 102$ & $\$ 226$ & $\$ 206$ & $\$ 433$ & $\$ 51^{b)}$ & --- & $\$ 126$ \\
\hline
\end{tabular}

${ }^{2}$ of the 858 defendants in the sample, 584 had bond set at $\$ 500$ or more, 253 were released on their own recognizance ( $1 . e .$. So bond), 1 had a $\$ 0$ bond but a cash alternative, and 20 had bond set between $\$ 20$ and $\$ 300$. For the latter group, 15 had a bond of $\$ 100$ or less wich is roughly equivalent to a cash alternative.

one defendant had a cash alternative of $\$ 1$ and the other a cash alternative of $\$ 100$. Note that no other defendants in the sample had cash alternatives of $\$ 1$. In fact, only 7 of the 147 defendants with cash alternatives had cash alternatives of less than $\$ 50$. 
The Probability of Pretrial Release

In theory, monetary requirements should have a significant negative effect on ths probability of pretrail release since the greater the "price" the defendant is required to pay to obtain pretrial release, the more likely it will exceed the maximum he is willing to pay, and the less likely he will be released. The maximum amount the defendant is willing to pay (given the length of time of pretrial detention and the probability of reapprehension if released) will be positively related to the opportunity cost of his time, his wealth, the value he places on the non-pecuniary aspects of pretrial liberty net of consumption provided him in prison, and any reductions in the expected future values of these variables resulting from pretrial detention (for example, lower expected future earnings if pretrial detention raises the probability of conviction). $23 /$

Table 6 presents data on the proportion of defendants released crossclassified by the size of bond and the option of a cash alternative. At one extreme--the distinction between defendants not required to post any bond and those required to pay something--monetary factors have a significant effect on reducing the probability of pretrial release. Of the 333 defendants released prior to the disposition of their cases, 253 were released on their own recognizance ( i.e., 100 per cent of those with a $\$ 0$ bond) while only 13.2 per cent (i.e., 80 defendants) of defendants required to post bond or pay a cash alternative were released. 24/ This result is not surprising since our sample consists of Legal Aid defendants; i.e., persons in the lower tail of the income distribution where a relatively small financial requirement is likely to exceed the maximum amount they are able to pay. We also observe that at each level of bond (greater than zero) the proportion released is substantially greater for 
Table 6

Pretrial Release by Size of Bond and by Cash

Alternative Option

\begin{tabular}{|c|c|c|c|c|c|c|c|c|c|}
\hline & \multicolumn{9}{|c|}{ Size of Bond } \\
\hline & \$o & $\$ 20-300$ & $\$ 500$ & $\$ 1000$ & $\$ 1500$ & $\begin{array}{c}\$ 2000- \\
3000\end{array}$ & $\begin{array}{c}\$ 3500- \\
5000\end{array}$ & $\begin{array}{l}\$ 7500- \\
20,000\end{array}$ & Total \\
\hline \multicolumn{10}{|c|}{ Cash Alternative } \\
\hline No. & 1 & 2 & 120 & 18 & 4 & 3 & 2 & --- & 150 \\
\hline Released & 0 & 50.0 & 31.7 & 38.9 & 25.0 & 33.3 & 50.0 & & 32.7 \\
\hline \multicolumn{10}{|c|}{ No Cash Alternative } \\
\hline No. & 253 & 18 & 137 & 113 & 52 & 82 & 43 & 10 & $455^{a}$ \\
\hline \&eleased & 100 & 33.3 & 13.9 & 4.4 & 1.9 & 0 & 0 & 0 & $6.8^{a}$ \\
\hline
\end{tabular}

${ }^{a}$ Excludes defendants with $\$ 0$ bond. 
defendants given a cash alternative, and that for defendants without a cash alternative the proportion released sharply declines as the size of bond increases. It is apparent from Table 6 that monetary requirements set by the court have a strong bearing on the pretrial status of defendants.

In order to measure the relative importance of variations in bond and cash alternatives and the effects of other variables (for example, socioeconomic factors) on pretrial status, multivariate analys is is required. However, the presence of a dichotomous dependent variable (i.e., the defendant is either released or not released) creates a problem in the choice of the appropriate statistical method.

One approach is to treat a dichotomous dependent variable as if it were a continuous variable, and estimate by ordinary least-squares (OLS) a linear probability function of the form

$$
P_{r_{i}}=\alpha_{0}+\alpha_{1} v_{i}+u_{i}
$$

where $P_{r_{i}}$ is the probability of pretrial liberty for the $i$ th defendant (which takes the value 1 if the defendant is released and 0 if he is not) and $\alpha_{i}$ and $v_{i}$ are vectors of regression coefficients and independent variables respectively. Several problems arise from the use of OLS in the case of a dichotomous dependent variable. These include the sensitivity of the estimated regression coefficients to the location of the explanatory variables (particularly, to extreme values), the inapplicability of the usual tests of significance of the estimated coefficients, the possibility that predicted values of some observations may be negative or greater than one, and the heteroskedasticity of the residuals. To avoid these difficulties we chose a maximum likelihood method of estimating a logit model where the logit specification of the probability function 
is the following:

$$
P_{r_{i}}=\frac{1}{\left[1+e^{-\left(\beta_{0}+\beta_{1} V_{i}+u_{i}\right)}\right.} \text {. }
$$

The maximum likelihood method handles individual observations, restricts the predicted values of the probability to between 0 and 1 , and yields asymptotic t-ratios that enable one to test the significance of the estimated coefficients. $25 /$

The coefficients in (3) are easily interpreted. For example, let $\beta_{k}$ equal the coefficient on the variable $v_{k}$ (where $v_{k}$ denotes one of the independent variables in (3)). We have

and

$$
\frac{\partial \log \left(P_{r} /\left(1-P_{r}\right)\right)}{\partial V_{k}}=B_{k}
$$

$$
\frac{\partial P_{r}}{\partial V_{k}}=\beta_{k}\left(1-P_{r}\right) P_{r}
$$

Since $P_{r} /\left(1-P_{r}\right)$ equals the odds of being released on bail, $\beta_{k}$ equals the proportionate change in the odds per unit change in $v_{k}$. The derivative, $\partial \mathrm{P}_{r} / \partial V_{k}$, when evaluated at the mean probability of committing a crime allows us to compare directly the logit results with the regression coefficients derived from the linear probability model.

The logit specification of the probability or pretrial release (denoted as $P_{r_{j}}$ ) for the $i$ th defendant is the following:

$P_{r_{i}}=\frac{1}{\left[1+e^{-\left(\beta_{0}+\beta_{1} \text { BOND }_{j}+\beta_{2} C A_{1 j}+\beta_{3}\left(B O N D \cdot C A_{1}\right)_{j}+\beta_{4}\left(C A_{1} \cdot C A_{2}\right)_{i}+\sum_{j} \beta_{j} Z_{j i}+u_{j}\right)}\right] .}$ 
where the defendant's bond, the option of a cash alternative, and the dollar amount of the cash alternative are denoted by BOND, $\mathrm{CA}_{1}$ and $\mathrm{CA}_{2}$ respectively, and where $z_{j}$ is a vector of socio-economic characteristics defined in Table 3. $26 /$

One predicts that an increase in the defendant's bond will lower the probability (or odds) of making bail, that the option of a cash alternative will raise the probability, and that an increase in the dollar amount of the cashalternative (given this option) will lower the probability. 27/ The interaction variable $\mathrm{BOND} \cdot \mathrm{CA}_{1}$ is included to test the hypothesis that increasing the amount of the bond will have no effect on the probability of release when the defendant is given the option of a cash alternative. $\frac{28 /}{1}$ The probability estimates are limited, however, by the absence of data on variables that should affect the maximum amount the defendant is willing to pay for release ( e.g., non-pecuniary aspects of detention, and changes in future values of earnings and wealth), and by the availability of imperfect measures of other relevant variables. In the latter category are the socio-economic characteristics of defendants that are used to approximate both the opportunity cost of detention and the defendant's wealth. 29/

The logit equation in Table 7 shows that the bond and cash alternative option variables are highly significant determinants of the probability of pretrial release (as measured by the t-ratios on the appropriate interaction variables). The logit estimates indicate, for example, that if the defendant is not given a cash alternative (i.e., $\quad C A_{1}=0$ ), a $\$ 100$ increase in bond leads to a reduction in the probability of release by .036 (at the mean $P_{r}$ ) or by about 27 per cent. Alternatively, a $\$ 100$ increase leads to a 30 per cent reduction in the odds of pretrial release (for example, at the mean odds this is a reduction from about .16 to .11). As predicted, increasing 
Table 7

27.

Probability Function of Release on Bail

\begin{tabular}{|c|c|c|c|c|c|c|c|}
\hline \multirow[b]{3}{*}{$\operatorname{Var} .(V)$} & \multicolumn{3}{|c|}{$\begin{array}{l}\text { Maximum Likelihood Logit } \\
\left.P_{r_{i}}=1 /\left[1+e^{-\left(\beta_{0}+\beta_{1} B O N D .\right.} \cdot .\right)\right]\end{array}$} & \multicolumn{4}{|c|}{$P_{r_{i}}=\alpha_{0}+\alpha_{1}$ BOND $\ldots \ldots \ldots \ldots \ldots \ldots$} \\
\hline & \multicolumn{2}{|c|}{ LOGIT } & \multirow[b]{2}{*}{ (T-Ratio) } & \multicolumn{2}{|r|}{ OLS } & \multirow[b]{2}{*}{$\overline{(T-R a t i o)}$} & \\
\hline & Coeff. ( $\beta)$ & $\frac{\left.\partial P_{r}^{a}\right)}{\partial V}$ & & Coeff. & & & \\
\hline BOND & -.306 & b & $(4.18)$ & -.002 & & $(2.60)$ & \\
\hline $\mathrm{CA}_{1}$ & -.189 & b & $(.33)$ & .257 & & $(5.06)$ & \\
\hline $\mathrm{BD} \cdot \mathrm{CA}_{1}$ & .315 & $b$ & $(3.98)$ & .005 & & $(1.04)$ & \\
\hline $\mathrm{CA}_{1} \cdot \mathrm{CA}_{2}$ & -.0026 & b & $(1.31)$ & -.0004 & & $(1.89)$ & \\
\hline AGE & .003 & .0003 & $(.17)$ & .001 & & $(.35)$ & \\
\hline NYC & 1.74 & .203 & $(1.65)$ & .142 & & (2.13) & \\
\hline EMP & -.147 & -.017 & $(.42)$ & -.008 & & $(.25)$ & \\
\hline PREM & -.260 & -.030 & $(.67)$ & -.018 & & (.49) & \\
\hline INC & -.006 & -.0007 & $(.83)$ & -.001 & & $(.89)$ & \\
\hline CONSTANT & -1.872 & & $(1.46)$ & -.038 & & & \\
\hline$x^{2}(d f)$ & 99 (9df) & & & $R^{2}=.13$ & & & \\
\hline$n$ & 535 & & & $n=535$ & & & \\
\hline \multicolumn{2}{|c|}{$\begin{array}{l}\text { Interaction } \\
\text { Variables c) }\end{array}$} & $\operatorname{LOGIT}{ }^{d)}$ & \multicolumn{2}{|c|}{$\begin{array}{l}\text { Interaction } \\
\text { Variables }\end{array}$} & LOGIT $^{d)}$ & & OLS) \\
\hline \multicolumn{2}{|c|}{$\frac{\partial \log R}{\partial B O N D} / C A_{1}=0$} & -306 & \multicolumn{2}{|c|}{$\frac{\partial P_{r}}{\partial B O N D} \mid C A_{1}=0$} & $\begin{array}{l}-.036 \\
(4.18\end{array}$ & & $\frac{-.002}{(2.60)}$ \\
\hline \multicolumn{2}{|c|}{$\frac{\partial \log R}{\partial B O N D} \mid C A_{1}=1$} & $\begin{array}{l}.008 \\
(.29)\end{array}$ & \multicolumn{2}{|c|}{$\frac{\partial P_{r}}{\partial B O N D} \mid C A_{1}=1$} & $\begin{array}{l}.001 \\
(.29)\end{array}$ & & .003 \\
\hline \multicolumn{2}{|c|}{$\left.\frac{\partial \log R}{\partial C A_{1}}\right|_{B O N D=\$ 500} ^{C A_{2}=\$ 100}$} & $\begin{array}{l}1.120 \\
(3.82)\end{array}$ & $\frac{\partial P_{r}}{\partial C A}$ & $\begin{array}{l}\$ 100 \\
=\$ 500\end{array}$ & $\begin{array}{l}130 \\
(3.82)\end{array}$ & & .237 \\
\hline \multicolumn{2}{|c|}{$\frac{\partial \log R}{\partial C A_{2}} \mid C A_{1}=1$} & $(i .31)$ & $\frac{\partial P r}{\partial C A}$ & & $(1.0003$ & & (i.80) \\
\hline
\end{tabular}

a $\partial_{P_{r}} / \partial V$ is evaluated at the mean probability of release $(-.135)$.

b $\quad \partial P_{r} / \partial V$ is a combination of coefficients.

c $R=P_{r} /\left(1-P_{r}\right)$.

d T-ratios are in parentheses. 
the amount of bond produces no significant effect on the probability of release when the defendant is given the option of a cash alternative $\left(C A_{1}=1\right)$. The impact of a cash alternative can be illustrated as follows:

a $\$ 100$ cash alternative, assuming bond is set at $\$ 500$, will raise the defendant's probability of rease by .13 (at the mean probability) or by about 100 per cent. Similarly, this $\$ 100$ option increases the odds of pretrial release by slightly more than 100 per cent. We also observe that increasing the amount of the cash alternative by $\$ 100$ reduces the odds of pretrial liberty by about 26 per cent, though this effect is not significant (i.e., the t-ratio $=1.3$ ). In contrast to the bond and cash alternative variables, the socio-economic variables are not significant determinants of the probability of pretrial release. Except for the variable denoting residence in New York City, which has a positive and marginally significant effect on the probability of release, the t-ratios on the other socio-economic variables are all less than one. Moreover, a test on the joint significance of all five socio-economic variables (including NYC) is consistent with the hypothesis of no effect $\frac{30 /}{0}$ one explanation of the non-significance of these variables is that they are inaccurate estimates of a defendant's ability to finance bail because they do not reflect regularity of employment, past earnings, savings, etc. or because other sources of income (e.g., illegal sources) are negatively related to measures of legal employment, earnings and other income. 31/ Finally note that the OLS estimate of the probability function are quite similar in magnitude and significance to the logit equation. 


\section{Forecasting the Harm From Pretrial Release}

We observed in the regression analys is of Table 4 a significant statistical relationship between the size of bond and variables measuring the severity of the defendant's offense, his criminal record, and his socioeconomic characteristics. The crucial question is whether these variables also predict the amount of harm a defendant will do if released on bail (Hypothesis II, p. 12). If this question is answered affirmatively, then in combination with the analysis of bond and pretrial release in general, we will have identified an important social function of the existing bail system and provided a rationale for its existence. The two sources of harm we investigate are crimes committed during the period of pretrial release, and the disappearance of released defendants. Crimes During the Period of Pretrial Release

The expected harm from crimes committed during the period of pretrial liberty can be subdivided into two components: the probability of committing a crime (or crimes), and the severity of the crime. We examine first the former component. Unfortunately, the data available are not ideal and thus our findings must be interpreted with some caution. We lack data on the commission of crimes during the period of pretrial liberty by defendants released on bail on their current charge. 32/ Nevertheless, information can be derived on crimes committed during the period of pretrial liberty from the 59 defendants in our sample who at the time of the arrest on their current charge also have a pending charge. This group of defendants had in the recent past been arrested and charged with a crime (i.e., their pending charge), released on bail, and then rearrested and charged 
with committing a new crime during the period of pretrial liberty

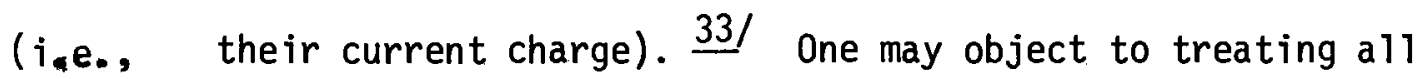
defendants with a pending charge as if they were identical to persons committing a crime during the period of pretrial release. Forty of the 59 defendants with a pending charge were in fact convicted on their current charge, 10 had their cases dismissed and 9 disappeared. On the other hand, to treat only the 40 convicted defendants as the group committing crimes during the period of pretrial release would eliminate some who actually committed crimes but were not convicted. Some "guilty" defendants may have had their charges dismissed because of a technicality, and there is no reason to presume that all defendants who disappeared did not commit crimes. In view of our ignorance regarding which group is most representative of defendants committing crimes, we present results for both a11 pending defendants ( 59 defendants) and pending defendants who are convicted (40 defendants). The former probably include some who did not commit crimes during the period of pretrial release while the latter group probably exclude some who did. (Hereafter, we refer to both groups as the "Pending Group", and when necessary distinguish between the two by the terms "A11 Pending" and "Convicted Pending".)

We can now compare the two Pending Groups with the group of defendants released on bail who have no pending charges (hereafter, the "Non-Pending Group".) The purpose of this comparison is to test whether there are significant differences in the characteristics of the Pending and Non-Pending groups (which would then be characteristics that forecast pretrial harm), and whether these characteristics are related to the factors that determine the size of bond. To illustrate, suppose we find that the Pending Group 
has a longer criminal record (at the time of their arrest on the pending charge) than the Non-Pending Group. This would indicate that prior criminal record provides information on the likelihood of committing a crime during the period of pretrial liberty. And one could infer that the reason prior record is used in setting bond is because of the information it conveys on pretrial harm. $34 /$

Table 8 contains for the Pending and Non-Pending groups the means and standard deviations of independent variables used in the bond regressions. Clearly, for the Pending group we desire variables recorded at the time of the pending offense since it is these values that are available to judges setting bond on the pending offense, and these values that are relevant to predicting the commission of an offense during the period of pretrial liberty ( $i . e .$, the current offense for persons with a pending charge). Data are available on the severity and type of pending charge. Unfortunately, there were no data relating to the pending offense for several variables entered in the bond regressions. 35/ Furthermore, several variables included in Table 8 for the Pending Group should be used with caution because they were recorded at the time of the arrest on the current charge and hence may have changed since the time of the pending charge. Specifically, data on employment, earnings, other income and residence in Table 8 were recorded at the time of the current arrest. Data on the type of offense (i.e., the eight dummy variables in the bond regression) are also excluded from Table 8 since a comparison of means is clearly inappropriate. (We pursue these variables with other statistical tests later on.) 
Means and Standard Deviations (in parentheses)

of Bond Regression Variables for the Pending and Non-Pending Groups a)

\begin{tabular}{|c|c|c|c|c|c|}
\hline \multirow{3}{*}{$\begin{array}{l}\left.\text { Variable }{ }^{b}\right) \\
\text { ASC }\end{array}$} & \multicolumn{2}{|c|}{ Pending } & \multirow{2}{*}{$\frac{\text { Non-Pending }}{(3)}$} & \multicolumn{2}{|c|}{ Difference } \\
\hline & Ail & Convicted & & & \\
\hline & $\begin{array}{l}4.61 \\
(5.51)\end{array}$ & $\begin{array}{l}5.63 \\
(6.28)\end{array}$ & $\begin{array}{l}3.15 \\
(3.79)\end{array}$ & $1.46^{\star \star}$ & $2.48^{\star \star}$ \\
\hline FEL & $\begin{array}{l}3.05 \\
(3.00)\end{array}$ & $\begin{array}{l}3.38 \\
(3.18)\end{array}$ & $\begin{array}{l}1.14 \\
(2.27)\end{array}$ & $1.91^{\star \star}$ & $2.24^{\star \star}$ \\
\hline MIS & $\begin{array}{l}4.97 \\
(4.54)\end{array}$ & $\begin{array}{l}5.80 \\
(4.92)\end{array}$ & $\begin{array}{l}1.75 \\
(3.33)\end{array}$ & $3.22^{\star \star}$ & $4.05^{\star \star}$ \\
\hline VIOL & $i^{44}(.93)$ & $\begin{array}{l}45 \\
\left.i^{4} .90\right)\end{array}$ & (19 & $.25^{\star}$ & $.26^{*}$ \\
\hline PAR & $\begin{array}{l}.09 \\
i .30)\end{array}$ & $\begin{array}{l}.06 \\
(.24)\end{array}$ & $\begin{array}{l}.02 \\
(.14)\end{array}$ & $.07^{\star \star}$ & .04 \\
\hline AGE & $\begin{array}{l}30.46 \\
(8.29)\end{array}$ & $\begin{array}{l}31.20 \\
(8.39)\end{array}$ & $\begin{array}{l}30.77 \\
(9.98)\end{array}$ & -.31 & .43 \\
\hline NYC & . ${ }^{95}(.23)$ & $\left.i^{97} .16\right)$ & $\left.i^{96} .20\right)$ & -.01 & .01 \\
\hline EMP & $\begin{array}{l}.50 \\
(.51)\end{array}$ & $i_{(.49)}^{38}$ & $i^{58}(.49)$ & -.08 & $-.20^{\star}$ \\
\hline PREM & $i^{14}(.35)$ & $i^{18}(.39)$ & $i^{18}(.38)$ & $=.04$ & 0 \\
\hline EARN & $\begin{array}{c}\$ 42.41 \\
(51.59)\end{array}$ & $\begin{array}{l}\$ 32.30 \\
(48.54)\end{array}$ & $\begin{array}{l}\$ 67.67 \\
(66.44)\end{array}$ & $-\$ 25.26^{\star \star}$ & $-\$ 35.37^{\star \star}$ \\
\hline INC & $\begin{array}{l}\$ 11.36 \\
(21.60)\end{array}$ & $\begin{array}{l}\$ 14.33 \\
(23.60)\end{array}$ & $\begin{array}{l}\$ 10.46 \\
(44.33)\end{array}$ & $\$ .90$ & $\$ 3.87$ \\
\hline$\underline{n}$ & 59 & 40 & 328 & & \\
\hline
\end{tabular}

a There are 59 defendants with a pending charge at the time of their arrest on the current charge and 40 of these were convicted on their current charge. 328 defendants are in the Non-Pending Group (defined as defendants relased on bail on the current charge who had no pending charge at the time of their arrest on the current charge). Note that the Non-Pending Group of defendants released on bail excludes 5 defendants with a pending charge who were released on bail on their current charge.

b ASC is the severity of the pending charge for the Pending Group and the severity of the current charge for the Non-Pending Group. FEL, MIS, and VIOL are prior record variables for the Pending Group at the time of their arrest on the pending charge, and hence the pending charge is not counted as a prior arrest. The remaining variables are all recorded at the time of the current arrest and, therefore, may be subject to error as estimates of their values at the time of the pending charge for the Pending Group.

Significant at .05 level for one-tail test $(t=1.65)$.

Significant at .01 level for one-taîl test $(t=2.35)$. 
The data in Table 8 present a striking picture of the differences between the two groups of defendants. The Pending group were accused prior to their release on bail with having committed a more severe crime (the ASC variable), had a record of more prior felony and misdemeanor arrests, had a greater proportion of persons on parole or probation, and had a lower average earnings than the Non-Pending group. $37 /$ On the other hand, there appear to be no statistically significant differences between the Pending and Non-Pending group in their age, residence, previous and current employment, and legitimate income (exclusive of earnings). Overa11, these results have an important bearing on understanding the operation of the bail system. They suggest that the variables that are statistically significant determinants of the defendant's bond (e.g., severity of the charge and criminal record) also provide information on the likelihood that a defendant will be charged with committing an offense during the period of pretrial liberty, and that the variables that are not significant determinants of bond ( e.g., age, residence, other income, previous employment) do not provide such information. One can infer, therefore, that the reason judges use the severity of the defendant's charge and his prior criminal record (and not the defendant's age, residence, previous employment and other income) as a guide in setting bond is because the first set of variables provides some information as to the likelihood that the defendant will commit a crime during the period of pretrial liberty.

Although the data in Table 8 provide insights into identifying the factors that predict crimes committed during the period of pretrial liberty, the analysis of one factor at a time does not allow us to estimate the net amount of information yielded by any one factor when all other factors are 
held constant. To do this we have estimated a probability function for pretrial crimes using the maximum likelihood method previously described. The logit specification of the probability function is the following $P_{c_{i}}=1 /\left[1+e^{\left.-\left(\beta_{0}+\beta_{1} X_{i}+\beta_{2} Y_{i}+\beta_{3} Z_{i}+\beta_{4} D_{i}+u_{i}\right)\right]}\right.$

where $P_{c_{i}}$ is the probability of committing a crime during the period of pretrial liberty for the $i$ th defendant (which takes the value 1 if the defendant is in the Pending group and 0 if he is in the Non-pending group). $X, Y, Z$ and $D$ are sets of variables defined in Table 3, although the variables included in each set (except for $D$ ) are limited to those contained in Table 8.

Estimates of the probability function of crimes committed during the period of pretrial liberty are presented in Table 9. Equations 9.1-9.3 are maximum likelihood Logit results where all defendants with a pending charge are included in the Pending group; equations 9.4-9.6 are also Logit results but the Pending group only includes defendants convicted on their current charge; and equations 9.7-9.8 are 0LS results that can be compared to 9.3 and 9.6 respectively. $38 /$

The findings in Table 9 are generally consistent with the results in Table 8 and the bond regressions in Table 4. Both the severity of the charge against the defendant and his criminal record (past felonies, past misdemeanors, parole but not past violations) have significant positive effects on the probability of committing crimes during the period of pretrial liberty. $39 /$ These findings are largely unaffected by which defendants are included in the Pending group, and by whether Logit or OLS techniques are used. The magnitude of the coefficients can be illustrated in the following examples. A defendant charged with a class $C$ felony, 
Table 9

Probability Function of Crimes Committed During

Pretrial Liberty

Maximum-Likelihood Logit

$p_{c_{1}}=1 /\left[1+e^{-\left(B_{0}+B_{1} A S C \ldots\right)}\right]$

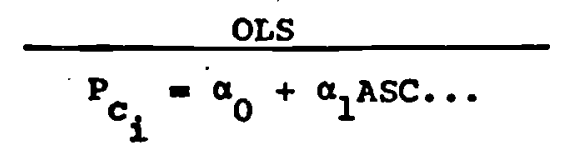

\begin{tabular}{|c|c|c|c|c|c|c|c|c|c|}
\hline \multirow{3}{*}{$\begin{array}{l}\text { Equation } \\
\text { var. (v) }\end{array}$} & \multirow[t]{2}{*}{ No. } & $(9.1)$ & \multirow[b]{3}{*}{$(T-\operatorname{ratio})$} & \multicolumn{2}{|c|}{$(9.2)$} & \multicolumn{3}{|c|}{$(9.3)$} & \multirow[b]{3}{*}{$(T$-ratio) } \\
\hline & & DGIT & & \multicolumn{2}{|c|}{ LOGIT } & \multirow[b]{2}{*}{ (T-ratio) } & \multicolumn{2}{|c|}{ LOGIT } & \\
\hline & Coofe $(\beta)$ & $\frac{\partial p}{\partial v}$ & & Coeff $(\beta)$ & $\frac{\partial P_{c}{ }^{a)}}{\partial v}$ & & Coeff $(B)$ & $\begin{array}{l}\partial P_{c}^{a)} \\
\frac{\partial V}{V}\end{array}$ & \\
\hline $\operatorname{AsC}^{(b)}$ & .069 & .009 & $(2.19)$ & .077 & .009 & $(2.33)$ & .077 & .009 & $(1.90)$ \\
\hline FEL & .121 & .016 & $(1.83)$ & .111 & .013 & $(1.61)$ & .116 & .014 & $(1.58)$ \\
\hline MIS & .143 & .018 & $(3.29)$ & .156 & .018 & $(3.28)$ & .144 & .017 & $(2.86)$ \\
\hline vIOL & .063 & .008 & $(.50)$ & .093 & .011 & $(.48)$ & .110 & .013 & $(.54)$ \\
\hline AGE & -.031 & -.004 & $(1.74)$ & -.031 & -.004 & (1.51) & -.024 & -.003 & $(1.01)$ \\
\hline PAR & & & & & &. & 1.502 & .178 & $(2.17)$ \\
\hline NYC & & & & & & & -.580 & -.069 & $(.77)$ \\
\hline EMP & & & & & & & -.085 & -.010 & $(.21)$ \\
\hline PREM & & & & & & & -.507 & -.060 & $(.92)$ \\
\hline $\begin{array}{l}\text { INC } \\
\text { DUM }\end{array}$ & & & & & & & $\begin{array}{c}.002 \\
x\end{array}$ & .0002 & $\begin{array}{l}(.60) \\
(3.9)^{f)}\end{array}$ \\
\hline CONST & -1.707 & & $(3.15)$ & -1.916 & & $(3.14)$ & -1.493 & & $(1.48)$ \\
\hline $\begin{array}{l}x^{2}\left(d_{.} f_{.}\right) \\
n\end{array}$ & $\begin{array}{l}41 \text { (5d.f } \\
387 \text { d) }\end{array}$ & & & $\begin{array}{l}40(5 d . f \\
357(d)\end{array}$ & & & $\begin{array}{l}51(16 d \\
357 d)\end{array}$ & & \\
\hline
\end{tabular}

a) Estimated at the mean probability which equals .152 in equation 9.1, .137 in equations 9.2-9.3, .109 in equation 9.4, and .097 in equations 9.5-9.6.

b) ASC is the severity of the pending charge for defendants with a pending charge, and the severity of the current offense for defendants without a pending charge.

c) Because of the limited number of observations (in some cases, zero) in some offense classes, six dummy offense variables are added in 9.3 and 9.7 , and five in 9.6 and 9.8. From the offenses 1 isted in Table 2, larceny, forgery and stolen property were aggregated into one offense class in 9.3 and 9.7 , and in addition, assault and dangerous weapon were aggregated in 9.6 and 9.8 .

d) Pending group includes all defendants with a pending charge.

e) Pending group includes defendants with a pending charge who are convicted on their current charge. 
Table 9 (continued)

Probability Function of Crimes Committed Duxing Pretrial Liberty

Maximum-Likelihood Logit

$P_{c_{1}}=1 /\left(1+e^{-\left(\beta_{0}+\beta_{1} A S C \ldots\right)}\right.$

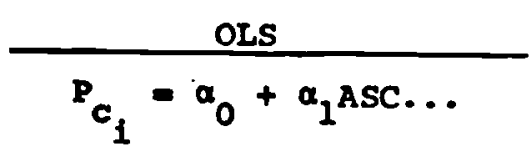

Equation No.

(9.4)

(9.5)

(9.6)

LOGIT

LOGIT

Var. (V) $\partial p_{c}^{a} \quad \overline{\partial p_{c}^{a)}}$

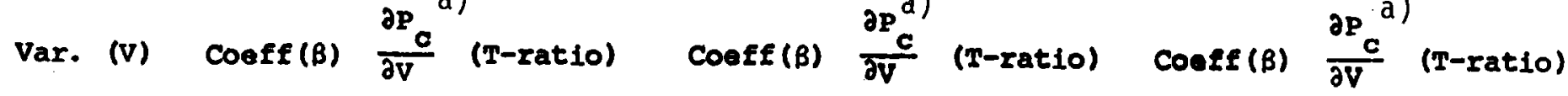

\begin{tabular}{|c|c|c|c|c|c|c|c|c|c|}
\hline $\operatorname{Asc}^{b)}$ & .104 & .010 & $(3.01)$ & .111 & .010 & $(3.01)$ & .085 & .007 & $(1.88)$ \\
\hline FET & .108 & .010 & $(1.44)$ & .102 & .009 & $(1.30)$ & .099 & .009 & $(1.21)$ \\
\hline MIS & .171 & .017 & $(3.53)$ & .179 & .016 & $(3.42)$ & .183 & .016 & $(3.21)$ \\
\hline VIOL & .028 & .003 & $(.19)$ & .100 & .009 & $(.47)$ & .177 & .015 & $(.77)$ \\
\hline AGE & -.029 & -.003 & $(1.35)$ & -.020 & -.002 & $(.85)$ & -.024 & -.002 & $(.92)$ \\
\hline PAR & & & & & & & 1.442 & .126 & $(1.47)$ \\
\hline NYC & & & ' & & & & .224 & .011 & $(.10)$ \\
\hline EMP & & & & & & & -.581 & -.051 & $(1.23)$ \\
\hline PREM & & & & & & & -.457 & -.040 & $(.73)$ \\
\hline INC & & ' & & & & & .003 & .0003 & $(.84)$ \\
\hline DUM C) & & & & & & & $x$ & & $\left.(3.2)^{g}\right)$ \\
\hline CONST & -2.450 & & $(3.73)$ & -2.931 & & $(4.05)$ & -2.709 & & $(1.92)$ \\
\hline$x^{2}(d . f)$. & \multicolumn{2}{|c|}{43 (5d.f.) } & & \multicolumn{2}{|c|}{41 (5d.f.) } & \multicolumn{4}{|c|}{$49(15 d . f)}$. \\
\hline $\mathbf{n}$ & $\left.368^{e}\right)$ & & & 341e) & & & $341 \mathrm{e})$ & & \\
\hline
\end{tabular}

Notes continued

f) $x^{2}$ statistic with 6 degrees of freedom is not significant.

g) $x^{2}$ statistic with 5 degrees of freedom is not significant.

h) F statistic with 6 and 340 degrees of freedom is not significant

i) F statistic with 5 and 325 degrees of freedom is not significant. 
Table 9 (continued)

Probability Function of Crimes Committed During Pretrial Iiberty

\begin{tabular}{|c|c|c|c|c|}
\hline \multirow[t]{2}{*}{ Equation No. } & \multicolumn{2}{|c|}{$\begin{array}{l}(9.7) \\
\text { OLS }\end{array}$} & \multicolumn{2}{|c|}{$\begin{array}{r}(9.8) \\
\text { oLs }\end{array}$} \\
\hline & coeff. (a) & (T-ratio) & Coeff. (a) & (T-ratio) \\
\hline Asc b) & .010 & $(2.22)$ & .010 & $(2.48)$ \\
\hline FEL & .016 & $(1.80)$ & .011 & $(1.48)$ \\
\hline MIS & .022 & $(3.58)$ & .023 & $(4.26)$ \\
\hline VIOI & .016 & $(.58)$ & .016 & $(.71)$ \\
\hline AGE & -.002 & $(1.09)$ & -.002 & $(1.00)$ \\
\hline PAR & .263 & $(2.61)$ & .151 & $(1.50)$ \\
\hline NYC & -.071 & $(.79)$ & -.006 & $(.07)$ \\
\hline EMP & -.011 & $(.26)$ & -.042 & $(1.16)$ \\
\hline PREM & -.050 & $(.92)$ & -.034 & $(.72)$ \\
\hline $\begin{array}{l}\text { Ine } \\
\text { Dum }\end{array}$ & $\begin{array}{c}.0002 \\
x\end{array}$ & $\begin{array}{l}(.56) \\
(.58)^{h)}\end{array}$ & $\begin{array}{l}.0003 \\
x\end{array}$ & $\begin{array}{l}(.74) \\
(.98)^{i)}\end{array}$ \\
\hline CONST & $\begin{array}{l}.168 \\
\mathrm{R}^{2}=.17 \\
357 \mathrm{~d})\end{array}$ & & $\begin{array}{l}.064 \\
R^{2}=.19 \\
\left.341^{e}\right)\end{array}$ & \\
\hline
\end{tabular}


compared to one charged with a class A misdemeanor, which adds 9.4 years to the ASC variable, has approximately a .09 greater probability of being charged with a new crime during pretrial liberty, other things constant. Since the mean probability of being charged is between .10 and .15 , a person accused of a class $C$ felony has about a 60 to 90 per cent higher probability of being arrested and charged with committing a crime during pretrial liberty than a person initially charged with a class A misdemeanor. Alternatively, each unit increase in the severity of the initial offense raises the odds of being charged with committing a crime during pretrial liberty by between 7 and 11 per cent. A unit increase in past felonies raises the probability of a pretrial crime on average by about .01 or roughly 7 to 10 per cent, or raises the odds by about 10 to 12 per cent. More strikingly, for a defendant on parole the probability of being charged with committing a crime during pretrial liberty rises by between .13 and .18 or more than 100 per cent and the odds increase by approximately 150 per cent. $40 /$ In sum, the results on severity of the offense and prior criminal record strongly support the hypothesis that these variables are positively related to the probability of committing crime during the period of pretrial liberty. Since it has previously been shown that judges set bail according to these same variables, we now have a powerful rationale for such procedure; namely, that severity of the initial charge and prior record provide judges with information on the likelihood of a defendant doing harm when released on bail. The remaining variables in the equations are generally not significant predictors (except for age, which is significant in 9.1 and marginally significant in 9.2 and 9.4) of the likelihood of committing a crime during pretrial liberty. For the residence (NYC), previous employment (PREM), 
other income (INC), and the type of offense variables (D), these findings are in accord with the earlier bond regressions (that is, these variables do not predict crimes during pretrial liberty and are not used in setting bond). On the other hand, employment or earnings, which had negative and significant effects on the size of bond in Table 4, have negative (as expected) but insignificant or marginally significant effects on the probability of committing a crime during pretrial liberty. $41 /$ We emphasize, however, that predictions about the likelihood of committing a crime need not be the sole criterion for setting bond. Forecasts on the severity of the crime and the likelihood that the defendant will not appear for future legal proceedings are also relevant.

Severity of Crime

We explore the question of severity using multiple regression analysis in which the dependent variable is the severity of the current charge (ASC). The sample is restricted to defendants with a pending charge (i.e., the Pending Group) since we are interested in the ability to forecast the severity of the crime committed during the period of pretrial 1iberty, given that a crime has been committed. The independent variables include the same variables used to forecast the probability of committing a crime during the period of pretrial release. The regression equations are presented in Table 10 where equation 10.1 includes all pending defendants and equation 10.2 includes pending defendants convicted on their current charge. The results of the two regression equations are quite similar except for the NYC variable, which is marginally significant in 10.1 but insignificant in 10.2. of particular interest is the prior felony variable which is a highly significant predictor of the severity of the offense committed during pretrial 
Table 10

Regressions on Severity of Current Charge for

Defendants with a Pending Charge

Equation No.

$(10.1)$

(10.2)

(10.3)

\begin{tabular}{|c|c|c|c|c|c|c|}
\hline & Sev & ity & $\mathrm{SE}$ & erity & & \\
\hline & Coeft. & (T-Ratio) & Coeff. & (T-Ratio) & Coeff. & (T-Ratio) \\
\hline $\mathrm{ASC}^{\mathrm{a}}$ & .020 & $(.15)$ & .015 & $(.11)$ & & \\
\hline FEL & .597 & $(2.34)$ & .683 & $(2.14)$ & -.003 & $(.04)$ \\
\hline MIS & .170 & $(.92)$ & .001 & $(.00)$ & -.032 & $(.65)$ \\
\hline VIOL & -2.323 & $(2.61)$ & -2.344 & $(1.82)$ & .137 & $(.91)$ \\
\hline AGE & -.196 & $(2.03)$ & -.204 & $(1.70)$ & .003 & $(.14)$ \\
\hline PAR & 1.101 & $(.54)$ & .202 & $(.06)$ & 1.176 & $(1.36)$ \\
\hline NYC & 4.091 & $(1.44)$ & -.372 & $(.07)$ & .465 & $(.54)$ \\
\hline EMP & .152 & $(.08)$ & 1.076 & $(.50)$ & -.815 & $(1.93)$ \\
\hline PREM & 1.020 & $(.42)$ & 1.784 & $(.63)$ & -.002 & $(.05)$ \\
\hline INC & -.063 & $(1.65)$ & -.069 & $(1.60)$ & -.005 & $(.90)$ \\
\hline DUM $^{b}$ & $x$ & $(1.85)^{d}$ & $x$ & $(1.10)^{d}$ & & \\
\hline CONST & 3.664 & & 10.181 & & 4.202 & \\
\hline$R^{2}$ & .47 & & .60 & & .01 & \\
\hline N & $49^{c}$ & & $33^{c}$ & & 716 & \\
\hline
\end{tabular}

ASC is average severity of pending charge.

b Four offense classes are used. Assault, dangerous weapon and robbery were aggregated into a "Crime agains Persons" class, and larceny, forgery, and stolen property were aggregated into an "other property" class. Note the Dumy offense variables refer to the pending offense.

C The number of defendants in 10.1 is less than the 59 defendants with a pending charge because 10 defendants had to be deleted because of the absense of parole and employment data. Similarly, 7 of the 40 convicted pending defendants were excluded because of lack of data and hence 10.2 contains 33 observations.

d F-ratio for 4 dummy variables. In neither regression was the F-ratio significant at the .05 level. 
liberty. This result together with the finding that prior misdemeanors is insignificant in Table 10 suggest why we observed in Table 4 that prior felonies had a greater impact than prior misdemeanors on the defendant's bond. Prior felonies predict both the probability and severity of the crime during pretrial liberty while prior misdemeanors only predict the probability. Of the two other criminal record variables, parole is insignificant while prior violations is significant. However, the more violations, other things the same, the less severe the crime during pretrial liberty. This appears to run counter to the hypothesis that the longer one's criminal record, the greater the harm from pretrial liberty. One possible explanation is the presence of serial correlation in the severity of crimes--that is, persons with more arrests in the past on violations, other things constant, are more likely to be arrested for violations in the future. $42 /$ However, the type of serial correlation is complex because the severity of pending charge (ASC) had an insignificant though positive effect on the severity of the crime during pretrial liberty. Thus, to the extent that serial correlation of severity exists, it does not run strongly from the immediate past charge (pending charge) to the current one but instead must reflect a pattern over several past offenses and the current offense.

The effects of the socio-economic variables in Table 10 should be viewed cautiously. As noted previously, NYC, EMP, EARN, PREM and INC are recorded at the time of the current not the pending arrest. Employment and earnings which had significant negative effects on the defendant's bond have no significant effect in predicting the severity of the current charge. $43 /$ Moreover, the Logit results of Table 9 indicated that 
employment and earnings had no significant effects on the probability of committing crimes during pretrial liberty. The effects of age in Table 9 and Table 10 indicate that older defendants have both a lower probability of committing crimes and commit less severe crimes during pretrial liberty. (The former effect is marginally significant while the latter effect is significant.) We have no explanation for the effects of age; however, it is apparent from the bond regressions that the information conveyed by age is not utilized in setting bond.

The power to predict the severity of crimes using prior information need not be confined to crimes during pretrial liberty. We can examine all defendants in our sample and ask whether prior information forecasts the severity of their current charge. Equation 10.3 presents the results for defendants without a pending charge, the majority of defendants in our sample. Here the prior criminal record variables have no significant effects on the severity of the current charge. The only significant variable in equation 10.3 is employment which shows that employed defendants are charged with committing less severe crimes. However, an F-test on the joint effect of the/set of independent variables leads us to accept the null hypothesis that jointly these variables have no significant power to predict severity. 44 Exactly why we have better success in forecasting severity of crimes committed during pretrial liberty remains an interesting puzzle.

\section{Disappearance}

The second source of harm from pretrial liberty is the disappearance of defendants released on bail. Disappearance frustrates the criminal proceedings against the defendant, gives released defendants added time to 
commit illegal acts, and generally weakens the deterrent effect of criminal sanctions. Data are available on the disappearance of defendants released on bail on their current charge, making it possible to test directly the determinants of the disappearance rate. 45 Since the dependent variable is dichotomous ( 1 if the defendant disappears and 0 if he does not), the estimation technique employed is the maximum likelihood Logit method described earlier.

Two questions are of interest in the analsyis of disappearance. First, are the factors that determine the size of bond also significant predictors of the probability of disappearance? Second, does the size of the defendant's bond and the presence of other financial requirements provide any deterrence to disappearing?

These two questions are interrelated. One stated purpose of the existing bail system (and many would argue the only "legal" purpose) is to deter disappearance by setting a money payment or bond that is forfeited if the accused does not appear in court. In theory, the higher the bond the greater the cost to the defendant of disappearing and hence the less likely he will disappear. This hypothesis has been widely challenged. It is argued that the use of professional bondsmen to post bonds for the defendant shifts the potential financial loss to the bondsman and removes the incentive for the defendant to appear at trial. This may be countered by arguing that the risks of disappearance are not shifted entirely because bondsmen require collateral and defendants are liable for the amount of the bond if it is forfeited. Further, bondsmen have incentives to protect their investment via the policing of defendants and informal mechanisms exist to ensure the appearance of defendants in continual trouble with the law 
(e.g., the prospect of not finding a bondsman in the future). Although arguments can be advanced for or against the deterrent effect the

of bond, the question of /actual effect on disappearance remains open because of the absence of empirical analysis. 46/ A second purpose for investigating the latter question is that bond and other financial factors must be held constant in order to test the hypothesis that the severity of offense, criminal record, etc. are predictors of disappearance. Assuming that the size of the defendant's bond deters disappearance, the failure to hold bond constant could lead to the conclusion that the severity of offense and criminal record have no effect on the incentive to disappear since whatever partial effect exists is offset by a higher bond. 47/

The Logit specification of the probability of disappearing $\left(P_{d_{j}}\right)$ for the $i$ th defendant is

$$
\begin{aligned}
& -\left(\beta_{0}+\beta_{1} B O N D_{i}+\beta_{2} C A_{1 i}+\beta_{3}\left(B O N D \cdot C A_{1}\right)_{i}+\beta_{4}\left(C A_{1} \cdot C A_{2}\right)_{i}\right. \\
& P_{d_{i}}=1 /\left[1+e^{\left.\left.+\beta_{5} X_{i}+\beta_{6} Y_{i}+\beta_{7} Z_{i}+\beta_{8} D_{i}+u_{i}\right)\right]}\right.
\end{aligned}
$$

where $X, Y, Z$ and $D$ are vectors of variables denoting severity of offense, criminal record, socio-economic characteristics, and type of offense respectively, and $B O N D, C A_{1}$ and $C A_{2}$ are financial variables. The specification in equation (7) of two interaction variables, $B O N D \cdot C A_{1}$ and $C A_{1} \cdot C A_{2}$, requires some explanation. The inclusion of $B O N D \cdot C A_{1}$ is based on the hypothesis that the deterrent effect on disappearing of increasing the defendant's bond will be weakened or even eliminated by giving the defendant the option of posting a cash alternative of a given amount. Thus, in equation (7) we expect $\beta_{1}$ to be negative and $\beta_{3}$ to be positive and of approximately the same magnitude as $\beta_{1}$. The interaction term $C A_{1} \cdot C A_{2}$ is simply the dollar value of the cash alternative ( ince if $\mathrm{CA}_{2}>0$, then $C \mathrm{CA}_{1}=1$ and if $\mathrm{CA}_{2}=0$, then $\left.C A_{1}=0\right) \cdot B_{4}$, the coefficient on $C A_{1} \cdot C A_{2}$, should be negative because the 
greater the amount of cash required for pretrial liberty the greater the amount lost if the defendant disappears. $48 /$ Table 11 presents both Logit and OLS estimates of the probability function of disappearance for defendants released on bail, and Table 12 evaluates the interaction variables in the probability function.

Tables 11 and 12 indicate that financial variables have some effect in deterring the disappearance of defendants released on bail. The only significant financial variable in the logit equation (at the .05 but not the .025 level of significance) is the size of the defendant's bond providing he is not given a cash alternative option. $49 /$ Here a $\$ 100$ increase in bond is associated with a .05 reduction in the probability of disappearing (at its mean value) or alternatively, with a 25 per cent reduction in the odds of disappearing for released defendants. More strikingly, a $\$ 500$ increase in bond reduces these odds (at their mean value) from .377 to .124 (from about 4 in 10 to slightly more than 1 in 10) or by about 67 per cent. However, if the defendant is also given the option of a cash alternative, increases in bond have no significant effect (as predicted) in reducing the probability of disappearing. 50 The logit coefficients on the remaining combinations of financial variables presented in Table 12 are all insignificant and less than their respective standard errors. For example, giving a cash alternative to a defendant with a $\$ 500$ bond does not significantly alter the probability of disappearing. This is not surprising because the impact of a $\$ 100$ cash alternative should be felt primarily for large values of bond. When bond is raised to $\$ 1500$, a cash alternative of $\$ 100$ substantially increases the probability of disappearing (by .323 in Table 12) but again this effect is not significant. $51 /$ We also find that increasing the amount 
Table 11

Probability Function of Disappearance During Pretrial Liberty

$\frac{\text { Maximum Likelihood Logit }}{P_{d_{i}}=1 /\left[1+e^{-\left(\beta_{0}+\beta_{1} A S C\right)}\right]}$

$\frac{\text { OLS }}{P_{d_{i}}=\alpha_{0}+\alpha_{1} \text { ASC... }}$

Eq. 1 .

$(11.1)$
LOGIT coeff. (B) $\frac{\left.\partial p_{q} a\right)}{\partial v}$ (r-ratio) Coeff. (B) $\frac{\partial p_{d}}{\partial v}$
(1.89)

(.60)

b. (.91)

b (.60)

$\mathrm{CA}_{1}$

FEL

MIS

VIOL

AGE

PAR

DET

CON

WPN

INJ

RES

NYC

EMP

PREM

INC

DUM

CONST

$x^{2}(d . f$.

n

-.243
-.648
.165
-.0019

$-.042$

$-.081$

.071

$-.170$

$-.032$

$-.473$

2.19

$-.221$

.579

.205

2.540

$-1.000$

$-.073$

.260

$-.004$

$x^{C}$

1.018

307
-.008 (.78)

$-.016(.83)$

.014 (1.11)

$-.034(-.64)$

$-.006(-1.72)$

$-.094(-.41)$

.436 (3.71)

$-.044(-.64)$

$.115(.90)$

.041 (.55)

$.505 \quad(2.56)$

$-.199(-1.43)$

$.015(-.18)$

$.052(.56)$

$-.0008(-.62)$

(17.32)

(1.04)

$62.6 \quad(25)$
$(11.2)$
$(11.3)$
OLS

(T-ratio) coeff. (a) (T-ratio)

\begin{tabular}{|c|c|c|c|c|}
\hline & & & -.033 & $(2.00)$ \\
\hline & & & -.118 & $(.83)$ \\
\hline & & & .023 & $(1.25)$ \\
\hline & & & -.0001 & $(.13)$ \\
\hline-.050 & -.001 & $(.94)$ & -.007 & $(.87)$ \\
\hline-.121 & -.024 & $(-1.31)$ & -.011 & $(.75)$ \\
\hline .067 & .013 & $(1.11)$ & .010 & $(.93)$ \\
\hline-.105 & -.021 & $(-.41)$ & -.026 & $(.64)$ \\
\hline-.033 & -.007 & $(-1.77)$ & -.004 & $(1.50)$ \\
\hline-.326 & -.065 & $(-.30)$ & -.056 & $(.31)$ \\
\hline 1.918 & .382 & $(3.60)$ & .404 & $(4.01)$ \\
\hline-.197 & -.039 & $(-.58)$ & -.024 & $(.41)$ \\
\hline .297 & .059 & $(.50)$ & .075 & $(.77)$ \\
\hline .339 & .067 & $(.91)$ & .024 & $(.41)$ \\
\hline 2.199 & .438 & $(2.46)$ & .410 & $(2.78)$ \\
\hline-1.158 & -.230 & $(-1,70)$ & -.178 & $(1.34)$ \\
\hline .120 & .024 & $(.32)$ & -.002 & $(.03)$ \\
\hline .367 & .073 & $(.83)$ & .053 & $(.66)$ \\
\hline $\begin{array}{c}-.0043 \\
x^{c}\end{array}$ & -.0009 & $\begin{array}{l}(-.64) \\
(16.92) d\end{array}$ & $\begin{array}{c}-.0004 \\
x^{c}\end{array}$ & $\begin{array}{l}(.63) \\
(2.20)^{e}\end{array}$ \\
\hline .376 & 50.5 & $\begin{array}{l}(.82) \\
(21)\end{array}$ & $\begin{array}{l}.587 \\
R^{2}=.18\end{array}$ & \\
\hline 307 & & & 307 & \\
\hline
\end{tabular}

a Evaluated at mean probability of disappearance $=.274$.

b $\partial \mathrm{P}_{\mathrm{d}} / \partial \mathrm{V}$ is a combination of coefficients. (See Table 12).

C There are six dumny offense variables with stolen property, forgery and larceny aggregated into a single offense class.

d $x^{2}$ statistic with 6 degrees of freedom. e F-ratio with 6 and 281 degrees of freedom. 
Table 12

Evaluation of Interaction Variables in Probability Function of Disappearance During Pretrial Liberty a

\begin{tabular}{|c|c|c|c|c|}
\hline $\begin{array}{l}\text { Interaction } \\
\text { Variables } b\end{array}$ & LOGIT & $\begin{array}{l}\text { Interaction } \\
\text { variables C }\end{array}$ & LOGIT & OLs \\
\hline$\frac{\partial \log (R)}{\partial B O N D} \mid C A_{1}=0$ & $\begin{array}{c}-.243 \\
(1.89)\end{array}$ & $\frac{\partial P_{a}}{\partial B O N D} \mid C A_{1}=0$ & $\begin{array}{l}-.049 \\
(1.89)\end{array}$ & $\begin{array}{l}-.003 \\
(2.00)\end{array}$ \\
\hline$\frac{\partial \log (R)}{\partial B O N D} \mid C A_{1}=1$ & $\begin{array}{c}-.078 \\
(.60)\end{array}$ & $\frac{\partial P_{d}}{\partial B O N D} \mid C A_{1}=1$ & $\begin{array}{r}-.016 \\
(.60)\end{array}$ & -.010 \\
\hline $\begin{array}{l}\left.\frac{\partial \log (R)}{\partial C A_{1}}\right|_{\text {BOND }} ^{C A_{2}}=\$ 500\end{array}$ & $\begin{array}{r}-.018 \\
(.02)\end{array}$ & $\begin{array}{l}\left.\frac{\partial P_{d}}{\partial C A_{1}}\right|_{B O N D} ^{C A_{2}}=\$ 100 \\
{ }_{B O N D}\end{array}$ & $\begin{array}{r}-.004 \\
(.02)\end{array}$ & -.013 \\
\hline $\begin{array}{l}\left.\frac{\partial \log (R)}{\partial C A_{1}}\right|_{\text {BOND }} ^{C A_{2}}=\$ 1500\end{array}$ & $\begin{array}{l}1.628 \\
(.72)\end{array}$ & $\begin{array}{l}\left.\frac{\partial P_{d}}{\partial C A_{1}}\right|_{B O N D} ^{C A_{2}}=\$ 200 \\
=\$ 1500\end{array}$ & $\begin{array}{l}.323 \\
(.64)\end{array}$ & .307 \\
\hline$\frac{\partial \log (R)}{\partial C A_{2}} \mid C A_{1}=1$ & $\begin{array}{r}-.0019 \\
(-.25)\end{array}$ & $\frac{\partial P_{d}}{\partial C A_{2}} \mid c A_{1}=1$ & $\begin{array}{l}-.0004 \\
(.25)\end{array}$ & -.0001 \\
\hline
\end{tabular}

a coefficients are from estimates in Table 11.

$b_{k}=P_{d} / 1-P_{d}$.

C Estimated at mean probability of disappearance $=.274$. 
48.

of the cash alternative has a negative though insignificant effect on the probability of disappearing. Finally, note that Logit and OLS estimation methods yield approximately the same results for the financial variables.

The results of Table 11 indicate that the main determinants of the defendant's bond--the severity of the charge (ASC), prior felonies (FEL) and parole or probation status (PAR)--are not significant predictors of the probability of disappearing. In fact, the more severe the charge, the greater the number of prior felonies and the more likely the defendant is on parole, the lower the estimated probability of disappearance, other things constant. Although none of these coefficients approach significance, their negative signs hardly support the view that these variables are positive predictors of disappearing. Of the other variables in Table 11 only the presence of an outstanding detainer (DET) and resisting arrest on the current charge (RES) were positive and significant predictors of the probability of disappearing. In addition, both of these variables had a positive but nonsignificant effect on the defendant's bond (see Table 4). One should also point out that the coefficients on the age variable (AGE) are marginally significant in Table 11; indicating that older defendants are less likely to disappear. Age was also negatively related to the probability of committing crimes during pretrial liberty and to the severity of these crimes, though these results were significant in only a few equations. This information, however, was not utilized in setting bond where the regression coefficient on age was always less than its standard error. Six dummy offense variables were included in each equation in Table 11. The coefficients on these variables were generally insignificant but jointly they had a significant effect on the probability of disappearing. $52 /$ This contrasts 
with the absence of any significant joint effects of offense type in the bond regression or in the equation on the probability and severity of crimes during pretrial liberty.

Forecasting Harm: Some Concluding Remarks

Our empirical analysis has revealed that the main factors determining the defendant's bond are also significant predictors of crimes committed during the period of pretrial 1 iberty but that these same factors have little power in forecasting the relatively high disappearance rate (around 30 per cent) during this period. We have reproduced in Table 13 the relevant regression and logit coefficients from the earlier tables that illustrate this important finding.

All independent variables that are included in Table 13 were statistically significant in the bond regressions, and all were entered in the equations on pretrial harm. Four of these variables--the severity of the initial charge, prior felony arrests, prior misdemeanor arrests, and parole or probation status--had positive and significant effects on either the probability (odds) that the defendant commits a crime during pretrial liberty or the severity of the pretrial crime given its commission. That is, variables measuring the seriousness and extent of a defendant's criminal record provide information on the occurence of criminal acts during pretrial liberty. Data limitations allowed only incomplete analys is in the pretrial crime equations of several variables included in the bond regressions. $53 /$ However, the tests that were carried out suggested that the insignificant variables in both the equations on the probability and on the severity of pretrial crimes were also insignificant in the bond regressions. In contrast, none of the variables in Table 13 had any significant impact on the probability 
Table 13

Coefficients and T-Ratios from

Bond and Pretrial Harm Equations a)

Dependent Variables

\begin{tabular}{|c|c|c|c|c|c|c|}
\hline $\begin{array}{l}\text { Independent } \\
\text { Variables }\end{array}$ & BOND & $\frac{\log 0 \mathrm{dc}}{\mathrm{ALL}}$ & $\begin{array}{l}\text { s of Crime } \\
\text { CONVICTED }\end{array}$ & $A \overline{L L}$ & $\frac{\text { everity }}{\text { CONVICTED }}$ & $\begin{array}{l}\text { Log Odds of } \\
\text { Disappearing }\end{array}$ \\
\hline ASC & $\begin{array}{l}1.213 \\
(8.13)\end{array}$ & $\begin{array}{l}.077 \\
(1.90)\end{array}$ & $i^{085}$ & $i^{.020}$ & $\begin{array}{l}.015 \\
(.11)\end{array}$ & -.042 \\
\hline FEL & $\left(\begin{array}{l}947 \\
(4.31)\end{array}\right.$ & $\begin{array}{l}116 \\
(1.58)\end{array}$ & $\begin{array}{l}.099 \\
(1.21)\end{array}$ & $i \frac{597}{(2.34)}$ & $\begin{array}{l}.683 \\
(2.14)\end{array}$ & $\begin{array}{r}-.081 \\
(.83)\end{array}$ \\
\hline MIS & $\left(\begin{array}{l}257 \\
1.79)\end{array}\right.$ & $\begin{array}{l}.144 \\
(2.86)\end{array}$ & $\begin{array}{l}183 \\
(3.21)\end{array}$ & $\begin{array}{l}.170 \\
(.92)\end{array}$ & $i \begin{array}{l}.001 \\
.00)\end{array}$ & $\begin{array}{l}.071 \\
(1.11)\end{array}$ \\
\hline PAR & $\begin{array}{l}6.182 \\
(2.48)\end{array}$ & $\begin{array}{l}1.502 \\
(2.17)\end{array}$ & $\begin{array}{l}1.442 \\
(1.47)\end{array}$ & $\begin{array}{l}1.101 \\
(.54)\end{array}$ & $i^{202}(.06)$ & $\begin{array}{l}-.473 \\
(.41)\end{array}$ \\
\hline EMP & $\begin{array}{l}-2.145 \\
(1.73)\end{array}$ & $\begin{array}{r}-.085 \\
(.21)\end{array}$ & 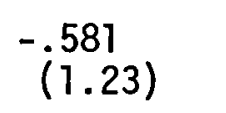 & $\begin{array}{l}.152 \\
(.08)\end{array}$ & $\begin{array}{l}1.076 \\
(.50)\end{array}$ & $\begin{array}{l}-.073 \\
(.18)\end{array}$ \\
\hline
\end{tabular}

a) For complete equations see 4.5 for BOND, 9.3 and 9.6 for the odds of pretrial crime, 10.1 and 10.2 for the severity of pretrial crimes, and 11.1 for the odds of disappearing. 
(odds) of disappearing. The only two significant predictors of disappearance (aside from the financial variables) were the outstanding detainer and resist arrest variables, and neither had a significant effect on the defendant's bond.

On the basis of these results, one can infer that judges are setting bond according to estimates of expected harm during the period of pretrial liberty, and that they are being guided in this decision by variables that are significant predictors of one type of harm; namely, crimes committed during the period of pretrial liberty. $\underline{54 /}$ Moreover, it would not be unreasonable to conclude that the principle social function of the existing bail system (as it operates in New York City) is to prevent defendants from committing additional crimes not from disappearing. $55 /$ This finding is in sharp contrast to the traditional view of bail which asserts that the sole legal purpose of money bail is to ensure the defendant's appearance at trial and that to use bail otherwise--that is, to prevent future criminal acts--is a violation of the Constitution. Critics of the criminal justice system are keenly aware of this conflict between theory and practice, and have argued at length that the actual operation of the bail system bears only a faint resemblence to its legal purpose. Many of these critics, however, deny that bail serves any useful purpose because they contend that judges and other law enforcement personnel do not have the information or skills to forecast pretrial crimes with any reasonable degree of accuracy. Our empirical analysis casts considerable doubt on this latter assertion. 56/

One is tempted to ask why judges behave as if they are more concerned with preventing defendants from committing crimes than from disappearing during pretrial liberty. Although a comprehensive answer is beyond the scope 
of the present study, it is useful to speculate on possible reasons.

Prima facie there appears to be an incentive for judges not to follow the policy outlined above because this policy is widely believed to be illegaland unconstitutional. Numerous scholars, public officials, appellate judges, and various organizations including the Legal Aid Society of New York and the Vera Institute have spoken out against the use of bail for purposes of preventing pretrial crimes. And in at least one instance a suit was brought challenging the constitutionality of the bail system. $\underline{57}$ In so far as judges are responsive to the criticisms of these groups or to possible sanctions (e.g., suspension or dismissal) from pursuing an "illegal" bail policy, then one is unlikely to observe the setting of bond based on estimates of future criminal activities. On the other hand, one can point to forces that may produce a response more consistent with our empirical findings. For example, if a defendant commits a crime during pretrial liberty and is apprehended, it is immediately apparent which judge was responsible for the defendant's release. In turn, the judge may receive adverse publicity depending on the severity of the defendant's crime, and the judiciary in general may become the target of public criticism against a legal system that is turning loose dangerous criminals. However, if a defendant disappears (assuming his case has not already received a great amount of notoriety), it is difficult to identify the judge responsible unless the defendant subsequently commits a crime and is arrested. Obviously, the relative importance of the opposing incentives cannot be determined a priori but requires a careful analysis of the explicit sanctions, rates of promotions, behavior of elected versus appointed judges, non-pecuniary benefits, etc. 
A related issue but one that is more specific to New York City is to ask what bail policy might be expected in a community where allegedly there is a crisis in law enforcement. Consider the following possible circumstances: crime rates are high and rising; a significant fraction of persons who are arrested and then released on bail fail to show up voluntarily for subsequent court appearances; only a small fraction of these defendants are reapprehended because of the limited enforcement resources and the large number of disappearances; defendants are rarely denied requests to delay their case and hence are able to put off for long periods the ultimate disposition of their case; and the resources of the prosecution are so strained by the large caseload and long delays that defendants, particularly, those free on bail, are offered trivial sentences in exchange for pleading guilty. One response to such a system is to punish and convict persons at the only stage that is often possible--the stage immediately after their arrest. That is, at the time of the defendant's arraignment, bond would be fixed at relatively high levels when there is a strong presumption of factual guilt. A higher bond would increase the likelihood of the defendant's pretrial detention, which is equivalent to immediate punishment, and would also increase the likelihood of future punishment following the disposition of his case. In these circumstances, bond and more generally the terms set for pretrial release serve as indicators of the judges estimate of both the defendant's factual guilt and the appropriate punishment. One should then observe a significant relationship between the size of bond and both the probability of conviction and severity of punishment, other things constant. Note that it is not necessary that using the bail system for the purpose of punishment 
would generate the features of bail that we have empirically observed. The link must be that defendants with more extensive criminal records and currently accused or more severe crimes are not only more likely to commit crimes if released on bail but are also more likely to be factually guilty. $58 /$ In the next section we attempt to gain incites into this question by examining the relationship between bond, pretrial detention and the disposition of cases.

\section{THE DISPOSITION OF DEFENDANTS}

In this section we analyze the empirical determinants of the disposition of cases. We make no attempt to examine the choice among different methods of disposition, particularly the choice between a settlement and a trial, since all but seven defendants in our sample had their cases disposed of without a trial. 59/ Instead we focus on the factors determining the sentence received by the defendant, including the important question of the effect of pretrial status on the sentence.

There are two main hypotheses regarding the relationship between pretrial status and the disposition of the case. The first asserts that defendants not released on bail are, as a consequence of their detention, more likely to be convicted and more likely to receive longer prison sentences than comparable defendants released on bail. One can argue that pretrial detention reduces the productivity of the defendants inputs into his case (both his own time and market inputs such as the services of an attorney). This in turn increases the probability of the defendant's conviction i.l a trial, which would weaken his bargaining power, and lead him to accept worse terms in a pretrial settlement. 60 / 
55.

The second hypothesis and one developed in the last section is that pretrial detention is the result of a greater probability of conviction adjusted for the severity of the offense. This is because judges supposedly use the setting of bond and other terms of pretrial release as a mecnanism for punishing defendants whom they believe are more likely to be convicted and to receive jail sentences. According to this hypothesis a finding of a positive relationship between detention and the severity of the sentence is expected; however, this would indicate that the sentence and not pretrial ietention was the causal factor. 61/

One can distinguish empirically between these two hypotheses by including as independent variables both the defendant's bond and his pretrial status in a regression equation on the defendant's sentence. If the second hypothesis is correct, one should observe a positive coefficient on the bond variable since the amount of bond incorporates information on the probability of conviction adjusted for the severity of the offense. If one still finds a negative effect of detention on the sentence with bond entered in the equation, this would then support the hypothes is that pretrial detention had an independent adverse effect on the defendant's sentence. Stated differently, if the regression were to exclude the defendant's bond, then the coefficient on the bail variable would be measuring both the effect of pretrial detention and the effect of prior information on the expected sentence (since the greater the bond, the greater the likelihood of pretrial detention).

Formally, we have the following recursive system of equations. 


$$
\begin{array}{r}
\text { BOND }=\alpha_{0}+\alpha_{1} X+\alpha_{2} Y+\alpha_{3} Z+u_{1} \\
\text { BAIL }=\beta_{0}+\beta_{1} \text { BOND } \\
\text { SENT }=\lambda_{0}+\lambda_{2} Z+u_{2} \text { BAIL }+\lambda_{2} \text { BOND }+\lambda_{3} X+\lambda_{4} Y+\lambda_{s} Z+u_{3}
\end{array}
$$

In equation (8) BOND is a positive function of the severity of the offense (the $X$ vector), prior record (the $Y$ vector) and socio-economic characteristics (the $Z$ vector). We have argued and provided substantial empirical evidence that the $X$ and $Y$ variables affect BOND because (a) judges set bond according to estimates of pretrial harm and (b) $X$ and $Y$ provide such information. We are now hypothesizing that BOND also includes predictions about the defendant's expected penalty. This expected penalty is in part related to the $X$ and $Y$ variables; however, the residual, $u_{1}$, also contains such information--presumably the greater the value of $u_{1}$, the greater the expected penalty other things constant. In equation (9), the defendant's pretrial status, denoted by BAIL (which is a dummy variable that equals 1 if the defendant is released and 0 if he is detained), is determined by the size of BOND (or, more generally, the terms of pretrial release) by the socio-economic variables. $62 /$ The sentence variable in turn is affected by pretrial status, plus information on the expected outcome (contained in the BOND variable), plus any additional effects due to the $X, Y$ and $Z$ vectors of variables. The failure to include the BOND variable in equation (10) would mean that BAIL would pick up the influence of BOND since $u_{1}$ is assumed to be positively correlated with the expected sentence and defendants released on bail are more likely to have negative $u_{j}$ 's

Table 14 presents the regression estimates of equation (10). The 
dependent variable in a11 equations is the defendant's sentence (SENT), which ranges from zero in the event of a dismissal or probation to 15 years (though only 18 defendants received sentences in excess of 1 year). .63 / The definitions of all independent variables are given in Table 3.

The most striking result in Table 14 is the positive and highly significant effect of the defendant's bond on his sentence. The importance of this effect is illustrated in the following examples. At the mean values of the other independent variables, a $\$ 0$ bond is associated with an average sentence of about 21 days, a $\$ 500$ bond with a sentence of 56 days, a $\$ 1500$ bond with a sentence of 125 days, and a $\$ 2000$ bond with a sentence of about 1 year. Since less than 3 per cent of our sample have sentences in excess of 1 year, it follows that variations in bond (within the range in which bond is set) can account for a large fraction of the average differences in sentences among defendants. These findings provide strong support for the hypothesis that at the initial stages of the criminal proceedings, judges are setting bond, in part, according to forecasts of the defendant's sentence. Thus, defendants likely to receive major penalties because they are accused of severe offenses or have lengthy prior racords will have relatively high bonds and tend to be detained. In contrast, defendants likely to receive minor sentences if convicted will have relatively low bonds and tend to be released. 64/ How does one interpret these empirical findings? We speculated at the end of Section III on the possible adaptation of a criminal justice system to a situation where disappearance rates are relatively high and resources for reapprehension are severely 1 imited. In these circumstances the determination of bond becomes the vehicle for effecting punishment because if the accused is released at this time, punishment becomes a remote possibility. $65 /$ 
Table 14

Regression Coefficients and T-values on the Sentence a)

\begin{tabular}{|c|c|c|c|c|c|c|}
\hline \multirow[t]{2}{*}{ Equation } & \multirow{2}{*}{$\begin{array}{l}\text { No. } \\
\text { Regression } \\
\text { Coefficients }\end{array}$} & \multirow{2}{*}{$\begin{array}{l}14.1 \\
\text { (T-value) }\end{array}$} & \multirow{2}{*}{$\begin{array}{l}\qquad 14.2 \\
\text { Regression } \\
\text { Coefficient } \\
\end{array}$} & \multirow[b]{2}{*}{ (T-value) } & \multicolumn{2}{|c|}{14.3} \\
\hline & & & & & $\begin{array}{l}\text { Regression } \\
\text { Coefficient }\end{array}$ & (T-value) \\
\hline BAIL & .016 & $(.246)$ & -.166 & $(2.514)$ & .041 & $(.580)$ \\
\hline BOND & .018 & (9.983) & -- & & .020 & $(10.041)$ \\
\hline \multicolumn{7}{|l|}{ DAYS-1 } \\
\hline \multicolumn{7}{|l|}{ DAYS-2 } \\
\hline ASC & .035 & $(5.927)$ & .057 & $(9.883)$ & .037 & $(5.677)$ \\
\hline FEL & .007 & $(.692)$ & .023 & $(2.083)$ & .006 & $(.509)$ \\
\hline MIS & .003 & $(.447)$ & .003 & $(.347)$ & .005 & $(.648)$ \\
\hline VIOL & .038 & $(1.894)$ & .036 & $(1.680)$ & .045 & $(1.961)$ \\
\hline PEND & .196 & (1.903) & .243 & $(2.215)$ & .259 & (2.167) \\
\hline AGE & .001 & $(.350)$ & .002 & $(.620)$ & .001 & $(.309)$ \\
\hline \multicolumn{7}{|l|}{ PAR } \\
\hline \multicolumn{7}{|l|}{ DET } \\
\hline \multicolumn{7}{|l|}{ CON } \\
\hline \multicolumn{7}{|l|}{ WPN } \\
\hline \multicolumn{7}{|l|}{ INJ } \\
\hline \multicolumn{7}{|l|}{ RES } \\
\hline \multicolumn{7}{|l|}{ NYC } \\
\hline \multicolumn{7}{|l|}{ PREM } \\
\hline \multicolumn{7}{|l|}{ EARN } \\
\hline \multicolumn{7}{|l|}{ INC } \\
\hline \multicolumn{7}{|l|}{ DUM } \\
\hline CONST & -.184 & & -.093 & & 0.213 & \\
\hline $\mathrm{R}^{2}$ & ,27 & & .17 & & .29 & \\
\hline$N$ & 725 & & 725 & & 643 & \\
\hline
\end{tabular}

a) Defendants who disappeared are excluded from all regressions. Equations 14.3 and 14.4 exclude defendants who were missing data on the independent variables. Equations 14.5-14.7 include only convicted defendants ( i.e., excludes disappearance and dismissals) because the length of time between arrest and disposition was not given for other defendants.

b) F-ratio with 8 dummy offense variables. 
Table 14 (continued)

\begin{tabular}{|c|c|c|c|c|c|c|}
\hline \multirow{2}{*}{$\begin{array}{r}\text { Equation } N \\
R \\
C\end{array}$} & \multicolumn{2}{|l|}{14.4} & \multicolumn{2}{|c|}{14.5} & \multicolumn{2}{|c|}{14.6} \\
\hline & $\begin{array}{l}\text { Regression } \\
\text { Coefficient }\end{array}$ & (T-value) & $\begin{array}{l}\text { Regression } \\
\text { Coefficient }\end{array}$ & (T-value) & $\begin{array}{l}\text { Regression } \\
\text { Coefficient }\end{array}$ & (T-value) \\
\hline BAIL & .029 & $(.386)$ & .112 & $(1.245)$ & & \\
\hline BOND & .019 & $(9.442)$ & .023 & $(9.814)$ & .021 & $(9.319)$ \\
\hline DAYS-1 & & & & & .005 & $(5.976)$ \\
\hline DAYS-2 & & & & & .001 & $(1.125)$ \\
\hline ASC & .028 & $(3.332)$ & .060 & $(7.370)$ & .041 & $(4.814)$ \\
\hline FEL & .005 & $(.439)$ & .009 & $(.663)$ & .010 & $(.755)$ \\
\hline MIS & .006 & $(.719)$ & .008 & $(.943)$ & .007 & $(.832)$ \\
\hline VIOL & .045 & $(1.921)$ & .062 & $(2.375)$ & .074 & $(2.936)$ \\
\hline PEND & .269 & $(2.143)$ & .151 & $(1.214)$ & .052 & $(.424)$ \\
\hline AGE & .0004 & $(.117)$ & -.002 & $(.568)$ & -.002 & $(.539)$ \\
\hline PAR & .067 & $(.483)$ & & & & \\
\hline DET & .072 & $(.733)$ & & & & \\
\hline $\mathrm{CON}$ & .074 & $(1.052)$ & & & & \\
\hline WPN & -.210 & $(2.147)$ & & & & \\
\hline INJ & .135 & $(1.991)$ & & & & \\
\hline RES & .016 & $(.106)$ & & & & \\
\hline NYC & .113 & $(.737)$ & & & & \\
\hline PREM & -.002 & $(.026)$ & & & & \\
\hline EARN & .0002 & $(.411)$ & & & & \\
\hline INC & -.0001 & $(.105)$ & & & & \\
\hline DUM & $x$ & $(1.185)^{b}$ & & & & \\
\hline CONST & -.369 & & -.224 & & -.215 & \\
\hline$R^{2}$ & .31 & & .38 & & .42 & \\
\hline N & 643 & & 504 & & 504 & \\
\hline
\end{tabular}


Table 14 (continued)
Equation No.
14.7

Regression

Coefficient (T-value)

$\begin{array}{lcl}\text { BAIL } & & \\ \text { BOND } & .022 & (8.405) \\ \text { DAYS-1 } & .006 & (6.232) \\ \text { DAYS-2 } & .001 & (1.506) \\ \text { ASC } & .023 & (1.866) \\ \text { FEL } & .010 & (.699) \\ \text { MIS } & .013 & (1.370) \\ \text { VIOL } & .084 & (2.836) \\ \text { PEND } & .172 & (1.204) \\ \text { AGE } & -.004 & (.951) \\ \text { PAR } & .082 & (.504) \\ \text { DET } & -.026 & (.054) \\ \text { CON } & .036 & (.411) \\ \text { WPN } & -.220 & (1.727) \\ \text { INJ } & .177 & (1.934) \\ \text { RES } & -.027 & (.159) \\ \text { NYC } & -.035 & (.190) \\ \text { PREM } & .034 & (.348) \\ \text { EARN } & .0002 & (.319( \\ \text { INC } & .0001 & (.052) \\ \text { DUM } & x & (1.526)^{b} \\ \text { CONST } & -.282 & \\ \text { R2 } & .48 & \\ \text { N } & 449 & \\ & & \end{array}$


This interpretation is clearly consistent with our empirical evidence.

It is more difficult to generalize on the effects of pretrial status. In equations $14.1,14.3$ and 14.4 there is no significant difference between the sentence of released and detained defendants, holding constant the other variables. $66 /$ In equation 14.2, we observe a significant positive effect of pretrial detention on the sentence ( i.e., a significant negative coefficient on BAIL) but this is due to the deletion of the bond variable. Once the latter is entered, as in equations $14.1,14.3$ or 14.4 , the significance of pretrial status is eliminated. On the other hand, equations 14.6 and 14.7 yield a different interpretation. In these equations the dichotomous bail variable was replaced by two pretrial status variables; DAYS-1 and DAYS-2 which are defined respectively as the number of days from arrest to disposition of the case for detained and for released defendants. 67/ (The means of these variables are 29 and 62 days respectively.) If pretrial detention has an adverse effect on the outcome, one might expect that the greater the amount of detention, as measured by days detained, the greater the defendant's sentence. Alternatively, there is no compelling reason to expect a relation between days at liberty (DAYS-2) and the sentence (assuming a disposition of the case). This is precisely our findings in equations 14.6 and 14.7. Although BOND continues to be the dominating variable, DAYS-1 has a positive and highly significant effect on the sentence, indicating that the greater the length of pretrial detention, other things constant, the more severe the sentence. $68 /$ In contrast, DAYS-2 is marginally significant and of smaller magnitude than DAYS-1. Pretrial detention, therefore, has an independent and adverse effect on the defendant's sentence but this is only observable when one differentiates according to the length of detention. 
We can summarize the results of the other independent variables in Table 14. (1) The severity of the charge (ASC), which is measured by the statutory penalty of the offense, has a significant positive effect on the sentence though the effect is diminished (as expected) by ineluding eight dummy offense variables in 14.4 and $14.7 .69 /$ The coefficients on ASC indicate that, other things constant, each year of a statutory penalty is associated with between 8 and 22 days of sentence, or a ratio of statutory penalty to sentence of between 43 and 17 to 1 This understates the total effect of statutory penalties because we have shown in Table 4 that severity is a significant determinant of the defendant's bond which in turn affects the sentence. The total effect of ASC must include the indirect effect operating through the defendant's bond. $70 /$ (2) of the other variables in the severity of offense group (CON, WPN, INJ and RES), only an injury to a complaining witness (INJ) has a significant positive impact on the sentence, and this effect is substantial. For example, a serious injury produces a direct effect on average of about 114 days plus an indirect effect via bond of between 36 and 55 days. $71 /$ (3) Since prior felonies, misdemeanors and parole or probation status are insignificant in Table 14, they only effect the sentence indirectly via bond. These indirect effects are weak for prior felonies and misdemeanors; for example, an additional prior felony arrest adds about 7 days to the sentence. The indirect effect of a defendant on parole or probation is about 45 additional days of sentence. The pending variable is significant and positive in equations 14.1-14.4, adding between 70 and 100 days to one's sentence, but insignificant when dismissals are excluded in equations 14.5 to 14.7 . Thus the significance of a pending charge 
in Table 14 is due to its role in reducing the likelihood of a dismissal. The estimated indirect effect of a pending charge is about 40 days. (4) All socio-economic variables have standard errors that are greater than their regression coefficients in Table 14 and hence are insignificant direct determinants of the sentence. Emplyment or legal earnings, however, will affect the defendants sentence via their influence in reducing bond. (5) The dummy offense variables, entered in 14.4 and 14.7, are jointly insignificant, indicating that the type of offense (given information on bond, severity of offense, etc.) is not a statistically significant factor in determining the defendant's sentence.

\section{CONCLUDING REMARKS}

At the outset we remarked on the widely held belief that the current operation of the criminal justice system is capricious and nearly random. According to this position, for example, the determination of bail and the disposition of cases would largely be the product of the whim of judges and others, and would not be systematically related to the nature and circumstances of the defendant's offense or his prior criminal record. This view is at variance with our analysis. The two major empirical findings of this study may be summarized as follows.

1. The defendant's bond and more generally the terms of his pretrial release were strongly influenced by various measures of the severity of the defendant's offense and his prior criminal record. Thus, the more severe the defendant's offense and the more extensive his criminal record, the greater the size of his bond and the lower the probability of his pretrial release. Severity and prior record were, in turn, significant predictors 
of crimes committed during the period of pretrial liberty but had little power in forecasting the relatively high disappearance rate (around 30 per cent) of released defendants. On the basis of these results it is not unreasonable to infer that the rationale for utilizing severity and prior record variables in setting bond is that these variables provide information on the expected harm from pretrial liberty where harm is measured by additional crimes.

2. The major determinant of the defendant's sentence was the size of his bond. Our explanation for this finding is that at the time bond is set judges are forecasting the likelihood of the defendant's conviction and the appropriate punishment. The forecast is then incorporated into the bail setting process by setting bond at relatively higher values for persons expected to receive more severe sentences, and setting bond at relatively lower values for persons likely to receive negligible sentences. We also observed that pretrial detention, as measured by days of detention, had an independent adverse effect on the sentence, though the dominating factor on the sentence was always the defendant's bond.

Are the above findings incompatible? On the one hand, bond incorporates information on the probability of pretrial crimes, and on the other, bond provides an estimate of the defendant's sentence. However, in a criminal justice system where disappearance rates are relatively high for released defendants and where 1 imited resources inhibit the reapprehension of defendants who disappear, punishment is only possible at the time of the arraignment, when bond is being set and the defendant is in the custody of the state. In these circumstances, setting bond according to the severity 
of the offense and prior record allows one to "kill two birds with one stone." A high bond serves the joint purpose of preventing pretrial crimes by detaining persons with higher probabilities of committing these crimes and of incarcerating persons most likely to receive jai] sentences on their current offense.

The use of the phrase "Legality and Reality" in the title of this paper should by now be apparent. The observed manner in which the bail setting process operates in New York City conflicts with the overwhelming view of the legal purpose of bail. To argue further that the bail setting process is capricious and serves no social purpose, however, is contrary to the evidence presented in this study. 
* This study is supported by a grant for the study of Law and Economics from the National Science Foundation to the National Bureau of Economic Research. I would like to thank Mrs. Ann Bartel for her assistance and comment; and Richard Posner for his comments. I would also like to thank the Legal Aid Society of New York for making their data available to me, and especially to Mr. Sam Dawson of the Society for helpful discussion of the data. This is not an official National Bureau publication as the findings reported herein have not yet undergone the full critical review accorded the National Bureau's studies, including approval by the Board of Directors.

1. See W. Landes, "An Economic Analys is of the Courts," Journal of Law and Economics, Apri1 1971, and "The Bail System: An Economic Approach," Journal of Legal Studies, January 1973.

2. For a detailed discussion of these two views of bail, see Herbert L. Packer, The Limits of the Criminal Sanction (1968), pp. 210-221, and W. Landes, "The Bail System: An Economic Approach," op. cit. 
3. The sample was developed by the Society not for the purposes of this study but for their own use in litigation in New York City. The Society filed a brief [Brief for Appellee, Bellamy v. Abruczo (N.Y. Sup. Ct., March 1972)] challenging the constitutionality of New York's bail system, and supported their challenge with extensive statistical analysis based on the sample.

4. There is one important exception. If a defendant disappeared and had not been reapprehended by the end of 1971, he was also placed in the closed files. This case is "completed" in the sense that the defendant has disappeared. We should point out that 133 defendants disappeared but only 95 disappeared who were released on bail. One might wonder how a defendant can disappear if he is not released on bail. Legal Aid attorneys have indicated to me that this is not so puzzling. Correction records are manually kept, records get misplaced, several defendants may have the same name (real or aliases), etc. The net effect is that a jailed defendant may not be located at the time of a scheduled court appearance. If he is not found shortly, he will be coded as having disappeared. Eventually, one hopes he will be found (that is, "reapprehended" by the Correction Department). The following quote from the N.Y. Times (October 5, 1973 on p. 35 under "Metropolitan Briefs") is illustrative: "Justice Leff declared a mistrial in State Supreme Court in Manhattan, blaming the Correction Department for failing to deliver one of three defendants in a robbery trial. . . Justice Leff said, 'I haven't the vaguest idea where Mr. Dollston is. He is somewhere in the custody of the Correction Department, and even they don't know where he is.' " 
5. 236,000 cases were filed in the Criminal Court of N.Y.C. in 1971 (see Annual Report of the Criminal Court of the City of New York, 1971). The Legal Aid Society reports 184,851 criminal case assignments in 1971 (see The Legal Aid Society 96th Annual Report, 1971), which represents 78 per cent of the cases filed in N.Y. C. Criminal Court. This figure overstates the number of completed cases by the Society since in some cases private counsel replaces Legal Aid counsel. (Based on a random sample of 423 cases of the Society's closed files, private counsel replaced Legal Aid in 12 per cent of the cases.) Assuming a 12 per cent replacement rate would reduce the per cent of cases handled by Legal Aid to 69 per cent.

6. The major discrepency between the sample and all New York defendants is that the former has a higher rate of guilty pleas and a lower rate of dismissals than the latter. This is probably explained by the fact that the N.Y. County and City data also include cases disposed of at the arraignment which tend to have a high rate of dismissals because of early decisions to drop prosecution when complaining witnesses do not show up or when the initial evidence appears inadequate. As indicated, the Legal Aid data exclude cases disposed at the arraignment. One should also note the slightly higher rate of disappearances in N.Y. County compared to our sample (23 compared to 19 per cent). This is expected since disappearances in N.Y. County are estimated by warrants issued after a defendant fails to appear. Since some of these defendants may subsequently reappear after the warrant is issued, the actual number of disappearances will be lower. A defendant is not counted as having disappeared in the Legal Aid sample if he reappears (before the end of 1971) after a warrant is issued on his initial disappearance. 
6. continued

Finally, note that the counties of New York City are not entirely homogeneous. For example, the disappearance rate in New York City is 31 per cent compared to 23 per cent for Manhattan. This is due to a 46 per cent disappearance rate in Brooklyn (i.e., Kings County).

7. The classification of offenses is generally based on the classification given in the N.Y. Penal Code. To limit the number of classes and to limit the number of defendants placed in the "other" category, we classified whenever possible a defendant into one of the eight categories. For example, the assault class includes defendants accused of menacing and reckless endangerment, and the burglary class includes persons arrested for possession of burglary tools and criminal trespass. The category of other offenses in Table 3 is a catch-all that includes among others: disorderly conduct, loitering, bribery, homicide (one defendant) and certain motor vehicle offenses such as unlicensed operation of vehicles and leaving the scene of an accident.

8. This hypothesis is derivable from an optimal bail system--one in which the number of defendants released is determined according to the criterion of maximizing a net benefit function from release (see Landes, "The Bail System: An Economic Approach," op. cit., particularly pp. 88-89). An increase in expected harm increases the marginal costs of release which in turn leads to a higher equilibrium price for release and a reduction in the probability of release. Harm may be broadly defined to include predictions about crimes committed by a defendant 


\section{8. continued}

during the period of pretrial liberty and the likelihood the defendant will disappear and thus frustrate the criminal proceedings against him. There is much disagreement over whether it is a violation of the Constitution for the first of these factors, predictions about future crimes, to enter the bail setting process. However, the sub rosa practice of setting high bail as a means of detaining defendants believed to be dangerous is widely acknowledged.

9. Any index of severity is bound to be somewhat arbitrary because of the selection of weights. For this reason we experimented with another index--felony $A$ equaled 8 , felony $B$ equaled 7 and so forth. The use of the latter as an index of severity instead of the one based on statutory penalties (the ASC variable) did not alter the results of our empirical analysis. A further difficulty with using ASC as an estimate of the offense is that some discretion is given to the authorities in determining the formal charge. For example, suppose two defendants commit identical offenses but the evidence against the first is stronger than against the second. If expectations about convictions are taken into account in fixing the formal charge, the first defendant may be charged with a more serious offense than the second.

10. Of course, the greater the injury to the victim, the more probable the formal charge will be adjusted upward. However, a given offense in the penal code need not specify the exact degree of injury and hence a range of injuries is consistent with a given formal charge. 
11. The resist arrest variable has a more obvious direct relation to expected harm and hence the size of bond. Assuming a positive correlation between current and future behavior, a defendant who resists arrest today will have greater expected costs of reapprehension if released on bail. And an optimal bail model predicts that the higher the costs of release, the greater the bond.

12. It can be argued that the promise of a low bond and hence a greater likelihood of release is used as a method of inducing the defendant to confess. If this were the case, a negative relationship between CON and BOND woluld be observed in the regression equation. Alternatively, it can be argued that a positive relationship would be observed because a confession indicates that the defendant's guilt has for all practical purposes been established and hence there is no reason to release him prior to the formal adjudication of his case. It is in the latter sense (i.e., confession indicates the defendant actualiy committed the offense) that the confession variable belongs in the severity of offense category.

13. If the $Z$ variables are in fact negatively related to the probability of disappearing and hence the expected costs of reapprehension, then $Z$ and BOND would be inversely related in an optimal bail system 
14. 95 defendants had to be deleted from the sample when all variables were entered because no information was available on one or more of these variables for each of the 95 defendants. The variable that resulted in the deletion of the most defendants was the employment or earnings variable which was missing for 77 observations. (Note that if employment was known earnings were generally reported; however, when a person was employed but earnings were not reported, we assigned the mean value to earnings for that observation.) To test if the deletion of 95 observations with missing values systematically altered the regression results we reestimated equation 4.1 using the smaller set of observations. This is equation 4.2 in Table 4 . A comparison between 4.1 and 4.2 reveals no significant differences. We should also point out that 254 out of 860 defendants had a zero bond (that is, these defendants were released on their own recognizance). When a sizable fraction of the sample has a zero valued dependent variable, the regression coefficients may be biased toward zero. However, a comparison of regressions where the zero bond defendants were deleted (these regressions are not included in the tables of the text) with regressions that included this group showed no important differences.

15. The differences in the regression coefficients on the felony and misdemeanor variables are statistically significant in the equations in Table 4. The t-statistics on these differences are in the range of 5.0. 
16. Data were also available on the number of felony arrests within 12 months of the current arrest, and the number that occurred more than 12 months before the current arrest. (FEL variable is the sum of the two numbers.) Similarly, misdemeanors and violations can be broken down in this manner. One can then test the hypothesis that greater importance is attached to more immediate arrests. This was done by defining 4 criminal record variables $\left(\mathrm{FEL}_{1}=\right.$ felony arrests within the last 12 months, $\mathrm{FEL}_{2}=$ felony arrests more than 12 montris ago, $\mathrm{M}-\mathrm{V}_{1}=$ misdemeanors plus violations within the last 12 months, $M-V_{2}=$ misdemeanors plus violations more than 12 months ago), and then reestimating equation 4.4 using these four variables instead of FEL, MIS, and VIOL. The regression coefficients and t-values (in parentheses) were as follows:

$\begin{array}{llll}\mathrm{FEL}_{1} & 3.37(2.8) & M-V_{1} & .41(.82) \\ \mathrm{FEL}_{2} & .84(3.6) & M-V_{2} & .26(1.8)\end{array}$

(We do not present the regression coefficients and t-values of the remaining variables in equation 4.4 since they were unaffected by this substitution.) These results suggest that not only are prior arrests, particularly felony arrests, important determinants of bond but that greater weight is given to more recent arrests in forecasting harm from pretrial liberty. The difference between the regression coefficients on $\mathrm{FEL}_{1}$ and $\mathrm{FEL}_{2}$ is substantial (that is, a recent felony arrest adds $\$ 337$ to the defendant's bond while a past felony arrest adds $\$ 84$ ) and statistically significant. The difference between $M-V_{1}$ and $M-V_{2}$ though positive is not statistically significant. 
17. One can get a rough notion of the source of the outstanding detainer by examining the proportion of defendants with detainers who are on parole and who have pending cases, and compare these proportions with the respective categories for all other defendants. The results below indicate that defendants with detainers are heavily represented in the parole and pending groups. For example, 23 per cent of defendants with detainers also have a pending charge whereas only 4 per cent of defendants without detainers have a pending charge, and 14 per cent with detainers are on parole while only 4 per cent without detainers are on parole.

\begin{tabular}{|c|c|c|c|c|}
\hline & Pending & No Pending & Parole & No Parole \\
\hline
\end{tabular}
No Detainers $\quad 4 \% \quad 96 \% \quad 4 \% \quad 96 \%$

18. In our sample, the current charge is never bail jumping for defendants with a pending charge.

19. A difficulty with statistically testing the effect of a pending charge on bond is the result of a selectivity bias in our sample. Certain characteristics of defendants on which data are not available (for example, the defendant's physical appearance, attitude, race, etc.) may result in the setting of a lower bond, raising the likelihood of the defendant's release. The fact that a defendant was released on bail on the earlier pending charge indicates that he probably possessed some of these favorable characteristics. If he still possesses them, this would operate to reduce the bond on the current charge (adjusting for the increase in his prior record). Hence, the pending variable could have an offsetting negative impact on bond. 
20. Although we find statistically significant effects on bond of the severity of offense and prior record variables, one might take the view that our analysis is deficient because we have only explained about 25 per cent of the variance (see the $R^{2} s$, in Table 4) in bond. However, it is not obvious that an $R^{2}$ of 25 per cent is not "high" given the nature of the dependent variable. Although bond in principle is a continuous variable, it tends in practice to be fixed at intervals of $\$ 500$. In our sample (see Table 5) we observe that 253 defendants had bond set at $\$ 0,20$ had bond between $\$ 20$ and $\$ 300,257$ had bond of $\$ 500,131$ had bond of $\$ 1,000$, 56 had bond of $\$ 1,500$, and so forth. With this distribution, in which the authorities do not make continuous and fine adjustments in the size of bond, we will tend to find sizeable residuals of predicted around actual values. This is reinforced by the use of a large number of independent variables in our regression equations which make it more likely that we will predict a continuous distribution of bond values.

21 When both the earnings and employment variables are entered in the same equation, neither is significant though both have a negative sign. The correlation coefficient between earnings and employed is .47 .

22. The F-ratio is 1.33 (with 8 and 739 degrees of freedom) which does not approach a conventional definition of significance. This nonsignificance is due in part to the fact that the severity of the charge variable (ASC) already incorporates information on the offense category. For example, robbery is either ${ }^{2}$ class $B, C$ or $D$ felony with 52 per cent of 
22 continued

robbery defendants accused of a class B felony. Larceny defendants are about equally divided between a misdemeanor $A$ and a felony $E$. Hence, a defendant accused of robbery will have a greater value for the ASC variable than a defendant accused of larceny. The association between the offense classes and the ASC variable can be tested by estimating an auxiliary regression of ASC on the eight dummy variables.

This is presented below where $D_{1}=$ assaillt, $D_{2}=$ burglary, $D_{3}=1$ arceny, $\mathrm{D}_{4}=$ robbery, $\mathrm{D}_{5}=$ stolen property, $\mathrm{D}_{6}=$ dangerous weapon, $\mathrm{D}_{7}=$ forgery, $\mathrm{D}_{8}=$ other, and the left out variable ( i.e., the constant in the regression) is drugs.

$$
\begin{aligned}
& \mathrm{ASC}=3.56+.85 \mathrm{D}_{1}+.30 \mathrm{D}_{2}-1.56 \mathrm{D}_{3}+8.67 \mathrm{D}_{4}-2.30 \mathrm{D}_{5}+.45 \mathrm{D}_{6}+.32 \mathrm{D}_{7}+.16 \mathrm{D}_{8} \text {. } \\
& \begin{array}{lllllll}
(1.89) & (.67) \quad(3.85) & (20.81) & (5.37) & (.77) & (.55)
\end{array} \\
& \mathrm{R}^{2}=.43 \text {. }
\end{aligned}
$$

The above regression indicates that 43 per cent of the variation in ASC is explained by the offense category of the defendant. A comparison of the regression equations 4.4 and 4.5 show that the main effect of introducing the eight offense variables is (as expected) to reduce the t-value of the ASC variable by about 30 per cent.

23 For a more complete analysis of the defendant's gain from pretrial liberty and the amount he is willing to pay for pretrial liberty see W. Landes, "The Bail System: An Economic Approach", op. cit.

24. Defendants are generally released on bail within a few days of their arrest. In our sample, 321 defendants were released within two days of their arrest and the remaining 12 were released within seven days of the arrest. 
25. See M. Nerlove and S. J. Press, "Notes on the Log-Linear or Logistic Model for the Analysis of Qualitative Socio-Economic Data," mimeographed August 23, 1972, for a systematic presentation of the logit model and an analysis of the problems associated with ordinary least squares estimation of a dummy dependent variable. Basically, the maximim likelihood method of estimating the logit model is as follows. Arrange the defendants so that the first $n^{\prime}$ defendants are released and the last $n-n^{\prime}$ defendants are detained, and then write the logarithmic likelihood function as

$$
\sum_{i=1}^{n^{\prime}} \log \left(P_{r_{i}}\right)+\sum_{i=n^{\prime}+1}^{n} \log \left(1-P_{r_{i}}\right)
$$

where $P_{r_{i}}$ is specified as in (3). The log likelihood function is then maximized with respect to $\beta_{0}$ and $B_{1}$. This yields a system of non-linear equations from which estimates of $B_{0}$ and the vector $\beta_{1}$ can be obtained by iterative procedures.

26. Defendants with a $\$ 0$ bond have a probability of release equal to 1 , and are, therefore, excluded from the estimation of the probability function.

27. Note that the dollar value of the cash alternative enters as the interaction term $\mathrm{CA}_{1} \cdot \mathrm{CA}_{2}$.

28. That is, $\partial \log \left(P_{r} /\left(1-P_{r}\right)\right) / 2 B O N D$ or $\partial P_{r} / \partial B O N D$ given that $C A_{1}=1$ should not be significantly different than zero. The specification in (6) defines $\partial \log \left(P_{r} /\left(1-P_{r}\right)\right) / \partial B O N D$ as equal to $B_{1}+B_{3} C A_{1}$, and $\partial P_{r} / \partial B O N D$ as equal to $\left(B_{1}+B_{3} C A_{1}\right)\left(P_{r}\left(1-P_{r}\right)\right)$. 
29. The socio-economic variables (EMP, EARN, INC, and PREM in Table 3) do not fully measure opportunity cost and wealth because among other things, they exclude earnings and wealth from illegal sources. The defendant's age (AGE) and residence (NYC) are also included as explanatory variables because both may indirectly reflect the defendant's access to assets for financing release and the willingness of bondsmen to post bond. For example, if it is less costly for bondsmen to supervise defendants living in New York City than those outside the City, posting bond for the former compared to the latter should lower the bondsman's risk of forfeiture of the bail bond. The predicted effect of age on making bail is uncertain. Although younger persons generally have fewer assets, they may have greater access to assets of parents.

30 The $x^{2}$ statistic (with 5 d.f.) on the joint effect of the socioeconomic variables is 2.72 . Note that earnings was also insignificant when it was entered in the logit equation in place of the employment variable.

31. This explanation is still consistent with using earnings or employment in setting bond (as was observed in Table 4) because judges may view only legal sources of income as indicators of one's attachment to the community. 
32. If this data were available, we could directly test whether the charactaristics of persons with respect to prior criminal record (i.e., prior to current charge), severity of current offense, etc. differed between defendants who were and were not subsequently convicted of crimes committed during the period of pretrial liberty. Even this data would be flawed because some offenders would not be caught and some convicted offenders may not have committed the alleged offense. Another possible and more subtle difficulty with such data, if it were available, is the following. Assume that prior criminal record and certain unmeasured (in our empirical analysis) characteristics of defendants are significant predictors of the likelihood of committing crimes during the period of pretrial release. Let judges be aware of these facts and let them set bond according to the defendant's record and these unmeasured characteristics. Defendants with both an extensive criminal record and adverse characteristics will have a high bond set and hence few or none of them will be released. Defendants with a similar criminal record but favorable characteristics will have a low or zero bond set and will be released. Hence, a sample of reieased defendants will contain some defendants with a long criminal record and some with no or an insignificant criminal record. However, the former group will contain primarily those with favorable unmeasured characteristics (since those with unfavorable characteristics will tend to be detained) while the latter group will have both defendants with favorable and unfavorable unmeasured characteristics. Consequently, we may observe no significant difference in the propensity to commit crimes during pretrial liberty between the two groups because we are not holding constant an important variable (i.e., the unmeasured characteristics). Note that if we still found a significant effect 
32 continued

of prior record on crimes committed during the period of pretrial release, then we would have found an even stronger effect if the unmeasured characteristics were held constant.

33. None of these defendants were rearrested solely on the bas is of a bail violation (for example, "jumping bail") on their pending charge. A bail violation may have been one of the charges against the defendant but it was not the most severe charge. The latter charge for all defendants in the sample involved a new criminal offense.

34. Comparisons between the Pending and Non-Pending groups will tend to understate the power of variables to forecast crimes during the period of pretrial liberty for two reasons. (1) We are assuming (incorrectly) that the Non-Pending group is equivalent to the group of released defendants who do not commit crimes during their period of pretrial liberty. Undoubtedly, the Non-Pending group includes some defendants who will in fact commit crimes during the period of pretrial release. This means that if defendants in the Pending group have on average significantly longer criminal records than those in the Non-Pending group, then we also expect the likelihood of committing crimes during the period of pretrial liberty among defendants within the Non-Pending group to bi greater the longer their criminal record. Hence, the observed difference in the average criminal record between the Pending and Non-Pending group should be smaller than the difference between the Pending ind a subset of the Non-Pending group, namely, those who do not commit crimes while released on bail. (2) Defendants released on bail 


\section{4 continued}

with long criminal records will tend to have other unmeasured characteristics that are favorable to low bond (otherwise it is unlikely they would be released) and these characteristics may be correlated with a low probability of committing crimes during pretrial liberty. (See footnote 32 for a more complete explanation of this point.)

One can roughly estimate the per cent of defendants in the NonPending group who will in fact be subsequently rearrested and charged wi ch committing a crime during the period of pretrial liberty. This can be illustrated by the following hypothetical figures. Suppose in period 1, 1000 persons are arrested and 400 are released on bail, and further assume that it takes one period to dispose of a case through the legal system. In period 2, 1000 persons are also arrested of whom 100 have pending charges against them, and again 400 are released on bail (though no one with a pending charge is released). Let these same figures persist in the future--1000 arrested, 400 released and 100 with pending charges. Since al1 cases are disposed of within one period, there are at most 400 persons at any moment in time who could commit an offense on bail. The number arrested and accused of committing an offens: while released is 100 , or 25 per cent of those released (which is equal to the ratio of pending to released in any one period). The use of the latter ratio as an estimate of the proportion of those released who commit a crime during the period of release would be less accurate if there were changes over time in some of the variables assumed constant. In our sample there are 328 defendants without a pending charge who are released on bail (i.e., the Non-Pending group) and 59 defendants with a pending charge. Thus, 18 per cent is a crude estimate of the proportion released who will be charged with committing a crime during the period of pretrial liberty. 
35. There were no data for the pending offense on the following variables: bond, confession prior to setting bond; possession of a dangerous weapon; injury to complaining witness; whether the defendant forcibly resisted arrest; and whether there existed an outstanding detainer. Note that it would be highly misleading to use the detainer variable at the time of the current charge because it may have been issued precisely because the defendant had a pending charge and committed a bail violation (e.g., jumping bail) during the period of pretrial liberty.

36. The parole and probation variable should be treated with caution since it is possible that some defendants with a pending charge may have been recorded on parole or probation (at the time of the current charge) precisely because they had a pending charge.

37. As noted earlier, the earnings and employment variables, which were recorded at the time of the current arrest, may have changed for the Pending group between the time of their pending and current charges. Moreover, the change need not be random since employment and earnings may be adversely afrected by the presence of a pending charge. Thus, the statistically significant difference between the Pending and NonPending groups for earnings and the marginal significance for employment may be spurious in the sense that they do not accurately reflect differences in these variables between the Pending group at the time the pending charge occurred and the Non-Pending group. 
38. Equation 9.1 differs from 9.2 and 9.3 because 30 observations had to be eliminated from the latter two equations to add the parole and the socio-economic variables. For an identical reason, equations 9.5 and 9.6 contain 27 fewer observations than 9.4.

39. The coefficient on past felonies is significant at the .05 level in equation 9.1 but its significance diminishes to .10 (in a one-tail test) in the remaining Logit equations. Moreover, the magnitude of the coefficients on past felonies are less than on past misdemeanors which suggests (surprisingly) that the latter has a bigger impact than the former on the probability of committing a crime during the period of pretrial liberty. One should not conclude, however, that greater weight should be attached to past misdemeanors than past felonies in setting bond since we have not yet examined the relationship between these criminal record variables and the severity of the offense committed during the period of pretrial liberty and the probability of disappearance.

40. This result should be interpreted with caution as indicated earlier in footnote 36.

41. The equations with earnings substituted for employment are not reproduced in Table 9. The coefficients and t-ratios (in parentheses) on earnings using the specification of equation 9.3 was $-.003(.81)$ and using the specification of equation 9.6 was $-.006(1.44)$. The remaining coefficients in these equations were virtually unchanged. 
42. This argument would also be applicable to our finding that past misdemeanors have an insignificant effect on the severity of the current charge.

43. The regression results on earnings (EARN) a:'e not presented in Table 10. When EARN was substituted for EMP in 10.1 and 10.3, it was insignificant.

44. The F-statistic is .90 with 9 and 706 degrees of freedom.

45. This was not possible in the analysis of crimes during the period of pretrial liberty because data were unavailable on which defendants released on bail on their current offense committed crimes.

46. If judges anticipate higher probabilities of disappearance and set bond accordingly, the empirical analys is is further complicated because the deterrent effect of bond may not be observable in a single equation model. That is, a higher propensity to disappear for a released defendant will be associated with a higher bond which in turn will offset the higher propensity. Therefore, one might observe identical probabilities of disappearance across defendants with different size bonds. We attempt to deal with this problem by holding constant variables likely to be associated with higher propensities to disappear (e.g., severity of offense and criminal record variables) when estimating the effect of bond and other financial variables on the probability of disappearance. 
47. There is an additional complication in estimating the partial effect of criminal record, etc. on disappearance that has already been discussed in connection with the commission of crimes during pretrial liberty (see footnote 32). For example, a defendant with a longer criminal record, holding constant bond and the remaining measured variables, would tend to have other (nonmeasured) characteristics that lead to the setting of a lower bond compared to a defendant with a shorter record. Assuming that the characteristics that reduce bond are favorable to appearing for court hearings, etc., then we may observe no significant positive effect of criminal record on disappearance (because of our failure to hold nonmeasurable characteristics constant) even though the true effect is positive. This means our empirical analysis will be biased against finding a significant positive effect of the criminal record variables, etc. on disappearance even though bond is held constant. Put differently, if the bail system is operating efficiently in the sense that judges are utilizing available information on the likelihood of disappearance to set bond, then defendants with long prior records who are released will primarily be those with other characteristics (that we cannot measure) that reduce the likelihood of disappearance. On the other hand, if judges are making "mistakes", then we should be able to pick out a positive effect of criminal record in the empirical analysis once bond is held constant because a longer criminal record will not be associated with favorable characteristics but rather with a "mistake" in setting bond. Indirect support for the latter interpretation comes from our findings on pretrial crimes. If 
47 continued

released persons with extensive prior records, etc. had some unmeasured favorable characteristics that reduce the probability of disappearing, we migit also expect these characteristics to be associated with the absence of pretrial crimes. The latter hypothesis, however, is not consistent with our empirical findings. In order to still advance the favorable characteristics hypothesis, one would then have to argue that these characteristics provide asymmetrical information (i.e., they are associated with less disappearances but not with less pretrial crimes). Without further evidence on the content of these unmeasured characteristics, this would be a highly tenuous argument.

48. The net effect of the cash alternative option on $P_{d}$ in equation (7) is $\partial P_{d} / \partial C A_{1}=\left[B_{2}+\beta_{3}(B O N D)+\beta_{4}\left(C A_{2}\right)\right] P_{d}\left(1-P_{d}\right)$. We expect $\partial P_{d} / \partial C A_{1}$ $>0$ except in the special case where the cash alternative is so large relative to the defendant's bond that it exerts the same deterrent effect on disappearing as bond. As indicated in the text, we expect $\beta_{3}>0$ and $\beta_{4}<0$.

49. A comparison of disappearance rates in relation to bond shows disappearance rates of 12.5 per cent $(10 / 80)$ for defendants with a positive bond or cash alternative and 33.5 per cent $(85 / 253)$ for defendants with a zero bond. Thus the ROR group (that is, released on their own recognizance) had nearly 3 times the rate of disappearances as the non-ROR group. Note that this comparison is for all 333 released defendants while the equations in Table 11 exclude 26 of these persons because of missing information on one or more independent variables. 
50. That is, one accepts the null hypothesis that $\beta_{1}+\beta_{3}=0$ in equation (7).

51. Part of the reason for an insignificant effect of a cash aiternative option is that the computation of the standard error of $\partial \mathrm{P}_{d} / \partial C A_{1}$ (or $\partial \log \left(P_{d}\left(1-P_{d}\right) / \partial C A_{1}\right)$ involves the standard error of $B_{3}$ in equation (7) weighted by bond-squared. Although the bond values used in Table 12 are moderate, they are still far greater than the mean bond in the sample of released defendants (about $\$ 140$ ) because about 75 per cent of the latter are released on their own recognizance (that is, a $\$ 0$ bond). Hence, the reliability of estimates of $\partial \mathrm{P}_{d} / \partial C A_{1}$ tend to be weak for values of bond that greatly exceed the mean value in the sample. Alternatively, if we were to use a lower value for bond in our computation, then the operational distinction between a bond and cash alternative would be destroyed, and in this instance $\partial \mathrm{P}_{d} / \partial C A_{1}$ would also be insignificant.

52. At the .05 level of significance (in a two-tail test) only the "other" offense class was significant in equations $11.1,11.2$ and 11.3. In both equations 11.1 and 11.2 the $x^{2}$ statistic on the joint effect of the dummy offense variables was significant at the .01 level. In equation 11.3 the F-ratio on the offense variables was significant at the .05 but not the .01 level. 
53. The following variables were not included in the probability of pretrial crimes or severity equations because of the absence of data: confession, possession of a dangerous weapon, resist airest, injury to a complaining witness, outstanding detainer and the amount of bond on the pending charge. Note that the injury variable was significant in the bond regressions. Further, the parole, residence, employment, earnings, other income and age variables are subject to inaccuracies because they were recorded at the time of the current and not the pending arrest. Finally, the pending charge variable, which was an important determinant of bond, cannot be included in the probability or severity equations because a crime committed during pretrial liberty is measured by the presence of a pending charge.

54. Two exceptions should be noted. First, as indicated, employment and earnings are significant variables in the bond regression but were not related to either crimes during pretrial liberty or disappearing. Thus, the purpose of setting a lower bond in response to legal employment and earnings remains unclear. Secondly, age was inversely related to all measures of harm (though in most cases the relationship was marginaliy significant) but was not used in setting bond.

55. Although we have shown that increasing the size of bond and withholding the option of a cash alternative has some deterrent effect on the probability of disappearing for a defendant released on bail, the important point is that judges are setting bond based on variables that forecast crimes and not disappearance. Put differentiy, reducing the 
24. F.

55 continued

rate of disappearance by setting more difficult terms for pretrial release may still be a goal of the bail system but according to our empirical results this goal would be equally/served by setting bond randomly among defendants. One rationale of setting bond on the basis of the severity and extent of one's prior record is to prevent defendants with greater probabilities of committing crimes from obtaining pretrial liberty. Note that one can never totally reject the hypothesis that judges are attempting to forecast the probability of disappearance in setting bond since it is conceivable that they are attempting to do so but are unsuccessfur in their efforts.

56. It must be noted that our empirical findings are not intended as either an indictment or defense of the existing bail system. We have quantified certain statistical relationships between bail setting and pretrial harm, but have not attempted to measure the social costs of operating the bail system in comparison to the gains from preventing pretrial crimes. For example, although the factors used in setting bond also predict pretrial crime, they may be subject to considerable error. Thus, detained defendants may have higher probabilities of committing crimes during pretrial liberty than those not released, and yet a majority of those detained may not commit any crime had they been released. Moreover, if the aim of public policy were exclusively the prevention of pretrial crime, the ideal solution would be to jail every defendant. 
57. The Legal Aid Society of New York brought a suit in 1972 (see Bellamy v. Abruczo, N.Y. Sup. Ct., March 1972) challenging the New York bail system. However, their major argument was that the use of money bail, which made it unlikely that low income defendants wou'd obtain pretrial liberty, was in violation of constitutional guarantees of equal protection of the laws and due process of law.

58. One may also argue that the systematic features of the setting of bond in New York City are not representative of the operation of all bail systems. Instead, these features are most applicible to a criminal justice system where large numbers of defendants disappear and hence where the imposition of criminal sanctions almost requires pretrial detention.

59. Of the remaining 851 defendants, 133 disappeared, 218 were dismissed, and 500 entered guilty pleas.

60. See W. Landes, "An Economic Analys is of the Courts," op. cit., pp. 71-73, 91-95 for an elaboration of the argument that pretrial detention reduces the productivity of the defendant's inputs together with some quantitative estimates of these effects using data across counties in the U.S. in 1962. It is also claimed that released defendants receive more favorable sentences if they are employed/regularly participate in a counselling program. Since these options are conditional on liberty, this would further widen the observed difference in sentences between detained and released defendants. 
61. Obviously the two hypotheses are not mutually exclusive. That is, persons with higher expected sentences may be more likely to be detained and detention may increase the expected sentence.

62. Estimation of equation (9) was by the maximum-likelihood logit method (see Table 7) where the dependent variable was the odds of pretrial liberty and not BAIL. Observations with a $\$ 0$ BOND were excluded from this estimation (weakening the negative effect of BOND on pretrial liberty) and several cash alternative variables were added to the estimated equations. Since the purpose here is not to reestimate (9) but to illustrate the recursive nature of our system, the linear specification without the cash alternative is sufficient.

63. Several problems arise in the estimation of the sentence equations. (1) No data are available on convictions resulting in fines. Hence some defendants would be included in the zero sentence class if they received only a fine. If the sentence included the option of a jail sentence or a fine, then the defendant's jail sentence would be the sentence variable in our sample.(2) There is some uncertainty as to the proper classification of/defendant who disappeared and hence where there is no formal disposition. Since disappearances are concentrated in the released group, their inclusion (by assigning a zero sentence to persons who disappear) in the regression would tend to bias upward the effect of pretrial detention on the sentence. Alternatively, disappearing is one way to avoid penalties (providing one is not reapprehended) and thus does reflect a real difference in 
63 continued

outcome between released and detained persons. The estimates in Table 14 exclude defendants who disappear. In a later footnote we indicate the sensitivity of the results to the inclusion of the disappearance group. (3) There are 388 defendants in our sample who received jail sentences. Thus only 54 per cent of our observations have a non-zero dependent variable (when defendants who disappeared are excluded from the analysis). Under these circumstances it is questionable whether ordinary least squares is the most appropriate estimation technique.

64. An alternative hypothesis that might appear consistent with the findings in Table 14 is that a high bond drains the defendant's resources and hence raises his conviction probability and sentence. This would imply, however, that variations in bond for detained defendants alone would have no impact on the outcome, other things constant. This can be tested by reestimating equation 14.1 for the subset of detained defendants. The regression coefficient on BOND continues to be positive and highly significant $(=.017$ with a t-value of 7.80) and of the same order of magnitude as the coefficient on BOND in 14.1 .

65. 13 per cent of released defendants received a jail sentence in comparison to 66 per cent of detained defendants. Since a large number of released defendants voluntarily appear for their court hearings, the probability of receiving a jail sentence is probably substantially smaller than .13 for defendants who disappear. 
66. Both this result and the result on the bond variable do not depend on the exclusion of defendants who disappear from the regression analysis. When these defendants are included, the reestimation of 14.1 which 858 defendants yields coefficients and (t-values) on BOND and BAIL respectively of .018 (11.135) and .031 (.580), and the reestimation of 14.4 with 764 defendants yields .019 (10.656) and .045 (.738) for BOND and BAIL respectively.

67. DAYS-1 and DAYS-2 are not available for persons who disappeared or whose cases were dismissed. Thus, regressions using the days variables contain at most 504 defendants or the subset of defendants that entered quilty pleas and went to trial. The deletion of dismissals means that 221 defendants who had a zero value for the sentence are dropped from the empirical analysis. Since dismissals are relatively concentrated in the released group (55 per cent of dismissals were released on bail compared to 23 per cent in the non-dismissed group) and in the lower bond values ( $\$ 775$ average bond compared to $\$ 1284$ for those not dismissed), one might expect the results on BOND and BAIL in 14.5-14.7 to be weaker. This may be offset by the large number of zero values for the dependent variable when dismissals are included which biases the regression coefficients towards zero. A comparison between 14.1 and 14.5, where 14.5 excludes dismissals, reveals that the elimination of dismissals does not alter our results on BOND and BAIL nor does it alter substantially the coefficients of the other independent variables. The similarity between 14.1 and 14.5 further suggests that inferences on the effects of the days variables in 14.6 and 14.7 are likely to hold up had data allowed all defendants to be included in the regression estimates. 
68. One reason for the observed effect of DAYS-1 may be that the sentence variable does not reflect the fact that a defendant receives credit towards his sentence for the amount of pretrial detention. Consider the following situation: a defendant detained for 60 days receives a sentence of 60 days and is released immediately after his guilty plea is formally entered, and another defendant detained for 30 days receives a 30 day sentence and is also released. Although in both cases the actual sentence is zero and hence there is no effect of pretrial detention, our empirical analysis would show a positive effect of detention on the sentence. To test for this we reestimated equations 14.6 and 14.7 , substracting from the sentence the amount of pretrial detention. Thus, if the latter exceeded or equalled the sentence measure in Table 14, we set the actual sentence equal to zero. The regression coefficients and ( $t$-values) on BOND, DAYS- 1 and DAYS-2 after this adjustment are given below.

\begin{tabular}{|c|c|c|c|}
\hline equation & BOND & DAYS-1 & DAYS-2 \\
\hline 14.6 & $\begin{array}{c}.021 \\
(9.361)\end{array}$ & $\begin{array}{c}.002 \\
(2.893)\end{array}$ & $\left(\begin{array}{l}.001 \\
(1.100)\end{array}\right.$ \\
\hline 14.7 & $\begin{array}{c}.021 \\
(8.408)\end{array}$ & $\begin{array}{l}.004 \\
(3.566)\end{array}$ & $\left(\begin{array}{l}001 \\
(1.483)\end{array}\right.$ \\
\hline
\end{tabular}

Although the effect of DAYS-1 is reduced (as expected) it is still positive and statistically significant. BOND remains highly significant and the dominating variable. Note that it is not obvious that the above adjustment is desirable. If the sentence (prior to our adjustment) has already been reduced for days detained, then our additional adjustment is clearly incorrect. 
69. See footnote 22 for the empirical relation between ASC and the offense variables.

70. Differentiating equation (10) with respect to ASC yields

$$
\frac{\partial(\text { SENT })}{\partial \mathrm{ASC}}=\lambda_{2} \frac{\partial \mathrm{BOND}}{\partial \mathrm{ASC}}+\lambda_{3}
$$

where $\lambda_{3}$ is the regression coefficient on ASC. Since $2 B O N D$; $2 A S C$ is approximately 1.4 (from Table 4) and $\lambda_{2}$ in Table 14 is nearly .02 , the ingtirect effect of one year of ASC is about .028 or about 10 days. Hence the total effect of one year of a statutory penalty is between 18 and 32 days of sentence. Indirect effects of other variables in equations (8) and (10) are calculated in an identical manner.

71. INJ was the only variable in the severity of offense group (aside from ASC) that was significant in the bond regressions in Table 4. Note that the total estimated effect of a non-serious injury to a complaining witness is half the effect of a serious one. 